\title{
Resistencia a la aspirina: un problema latente de alto riesgo
}

\author{
Aspirin resistance: a latent problem of high risk
}

\author{
Germán Campuzano-Maya MD
}

Resumen: La aspirina es la piedra angular del tratamiento en pacientes con enfermedades cardiovasculares y cerebrovasculares; sin embargo, varios estudios sobre la respuesta in vitro de las plaquetas a la administración de aspirina mostraron que esta respuesta es variable, encontrando algunos pacientes con falta de respuesta o resistencia a la aspirina. La resistencia a la aspirina puede ser «clínica» o «de laboratorio». La resistencia clínica a la aspirina se define como el fracaso para evitar la aparición de los episodios isquémicos aterotrombóticos en pacientes a los que se les administra. La resistencia de laboratorio a la aspirina se define como el fracaso de la aspirina para inhibir la producción de tromboxano $A_{2}$ por las plaquetas o para inhibir la activación de las plaquetas dependiente de la producción de tromboxano $A_{2}$. Hasta el momento no hay ningún método general para la evaluación ex vivo de la activación plaquetaria o del grado de activación de las plaquetas después de la administración de aspirina, y los datos relativos al impacto clínico de la resistencia a la aspirina son conflictivos. Por esto, no es posible sugerir directrices específicas para el tratamiento de pacientes que muestran altos niveles de activación plaquetaria o un bajo nivel de inhibición de las plaquetas después del tratamiento con aspirina. El objetivo de esta revisión es presentar los datos de estudios clínicos y de laboratorio que están relacionadas con la resistencia a la aspirina y discutir las posibles causas, importancia clínica y formas de manejo clínico de dicha resistencia.

Palabras clave: historia de la aspirina, ácido acetilsalicílico, aspirina, inhibidores de agregación plaquetaria, resistencia a la aspirina, métodos de seguimiento de la antiagregación plaquetaria con aspirina, detección de la resistencia a la aspirina.

\footnotetext{
${ }_{1}$ Médico, especialista en Hematología y Patología Clínica. Docente Ad Honorem, Facultad de Medicina, Universidad de Antioquia. Coordinador Grupo de Investigación en Patología Clínica. Médico Director, Laboratorio Clínico Hematológico. Medellín, Colombia. Correo electrónico: gcm@lch.co

Conflicto de intereses: el autor declara que no tiene conflicto de intereses Medicina \& Laboratorio 2016; 22: 13-54

Módulo 1 (La clínica y el laboratorio), número 114. Editora Médica Colombiana S.A. $2016^{\circ}$

Recibido el 23 de enero de 2016; aceptado el 27 de febrero de 2016
} 
Abstract: Aspirin is the cornerstone of treatment for patients with cardiovascular and cerebrovascular di43seases; however, several studies about in vitro platelet response to aspirin showed that this response is variable, with some nonresponding patients or had aspirin resistance. The aspirin resistance may be «clinical» or «by laboratory». Clinical aspirin resistance is defined as the failure to prevent the occurrence of atherothrombotic ischemic events in patients who were administered. Laboratory resistance to aspirin is defined as the failure of aspirin to inhibit thromboxane $A_{2}$ production by platelets or to inhibit platelet activation by a thromboxane $A_{2}$-dependent pathway. To date there is no general method for ex vivo assessment of platelet activation or the degree of platelets activation after administration of aspirin, and data concerning the clinical impact of aspirin resistance are conflicting. Therefore, it is not possible to suggest a specific guideline for treating patients with high levels of platelet activation or with a low level of platelets inhibition after aspirin treatment. The objective of this review is to present data from clinical and laboratory studies related to aspirin resistance, and to discuss possible causes, clinical importance, and forms of clinical management of this resistance.

Key words: aspirin history, acetylsalicylic acid, aspirin, platelet aggregation inhibitors, aspirin resistance, primary prevention, secondary prevention, cardiovascular diseases, cerebrovascular disorders, monitoring methods of antiplatelet therapy with aspirin, aspirin resistance detection.

Campuzano-Maya G. Resistencia a la aspirina: un problema latente de alto riesgo. Medicina \& Laboratorio 2016; 22: 13-54.

\section{L} as enfermedades cardiovasculares, incluidas las afecciones del corazón, del cerebro y de los vasos sanguíneos representan a nivel mundial la principal causa de muerte [1]. Se estima que el $1 \%$ de la población mundial puede presentar un evento cardiovascular o cerebrovascular por año y que cerca del $50 \%$ de estos eventos se presentan en pacientes con enfermedad vascular preexistente $[2,3]$ y que se pudieron haber prevenido con medidas tan simples como la antiagregación plaquetaria. Colombia no es ajena a esta problemática: la principal causa de morbimortalidad está relacionada con las complicaciones cardiovasculares, con una tasa de mortalidad estimada para 2008 de 124,2 y 122,9 por 100.000 hombres y mujeres, respectivamente $[4,5]$, con un aumento del 2,4\% por año, constituyéndose, por lo tanto, en un problema prioritario de salud pública [6]. Lo más grave de esta situación es que en el país no hay la cultura de la antiagregación plaquetaria [7], como sí existe en países como Estados Unidos en donde se consumen diariamente más de setenta millones de dosis de aspirina como prevención de eventos trombóticos [8]. 
Universalmente los enfoques para la reducción del riesgo cardiovascular, en la prevención primaria y secundaria, incluyen cambios del estilo de vida, por ejemplo, la dieta [9], la actividad física [10] y dejar de fumar [11] y mejorar la gestión de los factores de riesgo, por ejemplo, el buen control de la diabetes [12], la hipertensión arterial $[13,14]$ y los lípidos [15, 16]. Además de estas intervenciones, existe suficiente evidencia científica de que la antiagregación plaquetaria con medicamentos es una excelente alternativa para prevenir desenlaces fatales y, dentro de las varias decenas de medicamentos disponibles para lograr este objetivo, la aspirina, sola o combinada con otros antiagregantes, es la primera opción y la más utilizada en todo el mundo, tanto así que, por su probada eficacia clínica, costo-eficacia y perfil de seguridad, la Organización Mundial de la Salud (OMS) la ha incluido, en su dosis de $100 \mathrm{mg}$, en la lista de medicamentos esenciales en los servicios básicos de salud [17].

En los últimos años se ha observado en muchos pacientes que a pesar de tomar aspirina regularmente para prevenir complicaciones tromboembólicas en el sistema cardiovascular y cerebrovascular, igual a como puede suceder con otros antiagregantes plaquetarios, presentan estos eventos, lo que se ha denominado clínicamente como «falta de respuesta a la aspirina» y, más recientemente, como «resistencia a la aspirina» cuando se detecta con métodos de laboratorio, como se analizará en este módulo.

El objetivo de este módulo es revisar la resistencia a la aspirina en el contexto de la aspirina como antiagregante plaquetario, en donde se revisarán los aspectos históricos, los mecanismos de acción, los usos clínicos, el concepto de la resistencia al fármaco y los métodos de monitoreo de la antiagregación plaquetaria, entre otros aspectos. Este módulo es el resultado de una revisión exhaustiva de la literatura médica mundial sobre el uso de la aspirina como antiagregante plaquetario y la resistencia a la aspirina, utilizando el material disponible en la base de datos PubMed y la experiencia local con la antiagregación plaquetaria con aspirina y las pruebas de laboratorio para el monitoreo de la antiagregación plaquetaria, con aspirina y otros antiagregantes como el clopidogrel, y la oportuna detección de la resistencia a la aspirina u otros antiagregantes, cuando esta se presenta, antes de que se manifieste a través de las nefastas consecuencias trombóticas. Es importante que la comunidad médica incorpore estas medidas de prevención y que utilice las herramientas para controlarlas adecuadamente y que los laboratorios clínicos, al menos los especializados, incorporen esta tecnología para el seguimiento de la antiagregación plaquetaria y la detección oportuna de la resistencia a la aspirina.

\section{Historia de la aspirina}

La historia de la aspirina se remonta a los albores de la humanidad, cuando los salicilatos, sustancias derivadas de la corteza del salguero o sauce blanco (Salix alba), 
de la familia de las salicáceas, se utilizaron para tratar la inflamación y el dolor asociados con el reumatismo y otros procesos inflamatorios. Los sumerios, los egipcios y los chinos, entre otros más, utilizaban hojas de sauce como analgésico hace más de tres mil años. En el siglo $V$ antes de nuestra era, Hipócrates de Cos, el padre de la medicina griega, retomando antiguos conocimientos usó un brebaje de extracto de corteza y hojas de sauce (Salix latinum) como analgésico y antipirético [18, 19], que, coincidencialmente, son las mismas indicaciones que hoy tiene la aspirina. Quizás el documento más antiguo en donde se recoge el uso de los productos del sauce como analgésico y antipirético es en el papiro de Ebers, escrito entre los años 1600 y 1599 a.C., que constituye un tratado de medicina de la época en donde se relaciona el sauce blanco (Salix alba), que crecía en los humedales del río Nilo, con su uso en el tratamiento del reumatismo [20].

Durante la Edad Media los curanderos hervían la corteza del sauce y la daban a beber como un analgésico, pero esta pócima milagrosa pasó al olvido por una ley que prohibió descortezar y cortar las hojas de sauce, porque amenazaban la industria cestera de la época. Siglos más tarde, en la época moderna posrenacentista, en 1763, el clérigo inglés Edward Stone (1702-1768) presentó en Londres el beneficioso resultado obtenido en 50 pacientes con «fiebres reumáticas» tratados con infusiones de polvo seco de corteza de sauce [21], lo que, en la práctica, sería el primer estudio científico sobre el uso médico de los salicilatos. En 1828, Johan Andreas (Joseph) Buchner (1783-1852), profesor de farmacia en Múnich, desarrolló a partir de la corteza de sauce una masa amarillenta que denominó «salicina» [22] y, dos años más tarde, en 1830, el químico francés Henri Leroux convirtió la salicina en cristales e investigó sus propiedades antipiréticas [23]. Más adelante, en 1853, el químico francés Charles Frédéric Gerhardt (1816-1856) descubrió el ácido salicílico [24] y, en 1859, Herman Kolbe (1818-1884), obtuvo por síntesis química el ácido salicílico [25], pero este compuesto resultó con graves problemas para su uso, debido a su excesivo sabor amargo e irritación gástrica [26]. En 1897, el químico Felix Hoffmann (1868-1946) y el farmacólogo Arthur Eichengrün (1867-1949), de la compañía farmacéutica Bayer, en Alemania, sintetizaron en forma artificial el ácido acetilsalicílico, principio activo de la aspirina y, en 1899, el laboratorio Bayer inscribió esta molécula, bajo la denominación de «Aspirina ${ }^{\circledR} »$, en la Oficina Imperial de Patentes de Berlín como marca registrada de su propiedad [27]. El nombre de la aspirina se deriva del término «Spiraea», especie vegetal de la cual alguna vez se preparó el ácido acetilsalicílico [18].

\section{La aspirina como antiagregante plaquetario}

El conocimiento de la acción de los salicilatos sobre el sistema hemostático no es nuevo. En 1891, un científico alemán, C. Binz, observó que el ácido salicílico podía causar sangrado en las mucosas de los pacientes que lo consumían [28] y en 1940, Karl Link (1901-1978), padre de la warfarina, y sus colaboradores pos- 
tularon que la aspirina podía reducir la actividad de la protrombina y publicaron un informe en 1943 en relación con su efecto anticoagulante [29].

Podría asumirse que el camino al uso de la aspirina como antiagregante plaquetario se inició desde 1945, cuando en la literatura médica mundial se informó, una vez más, el riesgo hemorrágico por el consumo de la aspirina [30-32], especialmente, cuando se empezó a observar en pacientes sometidos a amigdalectomía [33], a quienes se les practicaban extracciones dentales [34] y a nivel gastrointestinal [35]. Inicialmente, las manifestaciones hemorrágicas fueron erróneamente atribuidas a una alteración en el tiempo de protrombina [36], hasta 1948, cuando Paul Gibson, en Inglaterra, sugirió que el ácido acetilsalicílico podría ser útil en el tratamiento de la trombosis coronaria [37] y al año siguiente presentó informes de casos que detallaban el papel de la aspirina en el tratamiento de la trombosis coronaria y de la angina de pecho [38].

El uso sistemático de la aspirina a pequeñas dosis como protector de la enfermedad tromboembólica, en particular de la trombosis coronaria, se remonta a la década de los años cincuenta del siglo pasado, cuando el Dr. Lawrence Craven (1883-1957), médico otorrinolaringólogo de Glendale, California, Estados Unidos, observó en su práctica privada que los pacientes sometidos a amigdalectomía, a quienes les indicaba que masticaran una goma conocida como Aspergum $^{\circledR}$ que contenía aspirina, sangraban excesivamente. A partir de este conocimiento, el Dr. Craven empezó a administrar aspirina para prevenir el infarto agudo de miocardio, llegando a administrarla a más de 8.000 pacientes [39-42], con publicaciones de circulación regional como Annals of Western Medicine and Surgery (Ann West Med Surg) [39], Journal of Insurance Medicine (J Insur Med) [40] y Mississippi Valley Medical Journal (Mississippi Valley Med J) [41, 42]. Como dato anecdótico, irónicamente, el Dr. Craven murió de un infarto agudo de miocardio a los 74 años de edad, a pesar de estar tomando la aspirina que promovía para sus pacientes [43, 44], que de ser así, podría ser una de las primeras víctimas de la resistencia de la aspirina, tema central de este módulo.

Años más tarde, en 1971, Sir John R. Vane (1927-2004), farmacólogo británico, demostró que el mecanismo de acción de la aspirina como antiagregante plaquetario era la inhibición de la síntesis de las prostaglandinas intensificadoras del dolor [45], siendo tan importante este aporte que lo hizo merecedor al premio Nobel de Medicina en 1982, junto con Begnt Samuelsson y Sune Bergstrom, «por sus descubrimientos en relación con las prostaglandinas y sustancias relacionadas biológicamente activas» [46].

Aunque así parezca, la resistencia a la aspirina no es nueva, se ha sospechado desde hace varias décadas, pero, por razones que nadie discute, solo en la última década se le ha tomado en serio, tras una publicación en el New York Times, en 2004, que llamo la atención sobre el hecho de que entre el $5 \%$ y más del $40 \%$ de 
los pacientes que tomaban aspirina para proteger su corazón no estaban protegidos debido a que presentaban una resistencia a la aspirina [47]. Revisando la literatura médica mundial la primera insinuación a la resistencia a la aspirina se debe a Mueller y colaboradores quienes, en 1985, describieron el caso de un paciente con infarto agudo de miocardio que tomaba aspirina, en el cual le diagnosticaron una resistencia a la prostaciclina [48], aunque otros la atribuyen, cinco años más tarde, a Ackerman y Newman en 1990 [49].

Finalmente, si bien la aspirina al principio se utilizó primordialmente como analgésico y antipirético, hoy su mayor formulación está dirigida a la prevención de las enfermedades trombóticas cardiovasculares y cerebrovasculares; es así como, a nivel mundial, la producción anual de aspirina está alrededor de 40.000 toneladas, con más de cincuenta millones de pacientes tomándola con fines de prevención cardiovascular y cerebrovascular tan solo en Estados Unidos [46, 50, 51].

\section{Estructura y función y fisiología de las plaquetas}

Antes de analizar el papel de la aspirina como antiagregante plaquetario es indispensable conocer con claridad la estructura, las funciones y la fisiología de las plaquetas, como se analizará a continuación.

\section{Estructura de las plaquetas}

Las plaquetas, también denominadas trombocitos, son fragmentos citoplasmáticos, pequeños, irregulares y carentes de núcleo, con un tamaño de $2 \mu \mathrm{m}$ a $3 \mu \mathrm{m}$ de diámetro, derivados de la fragmentación de sus células precursoras, los megacariocitos [52]. El recuento plaquetario en un individuo normal oscila entre 150.000 y 450.000 plaquetas por microlitro $(\mu \mathrm{L})$, la vida media plaquetaria oscila entre 7-10 días y, en el caso de no ser utilizadas, son retiradas de la circulación sanguínea por los fagocitos en el bazo y por las células de Kupffer en el hígado [52,53].En la figura 1 se muestra el megacariocito normal, célula poliploide procedente de la medula ósea, en donde se producen las plaquetas, y en la figura $\mathbf{2}$ se muestran las plaquetas normales en un extendido de sangre periférica.

Desde el punto de vista estructural, las plaquetas son una verdadera bomba de energía que en condiciones normales no se activa sino cuando sea necesario. En su superficie cuentan con diversos receptores que le permiten ejercer sus funciones biológicas. Estos receptores son en su mayoría glicoproteínas (GP), entre las que se encuentra el complejo GP Ib-IX-V, también conocido como el receptor del factor von Willebrand, que mediante la unión al factor von Willebrand, que cubre las fibras de colágeno en la herida (subendotelio), inicia la hemostasia causando la adherencia y el rodamiento de las plaquetas sobre la superficie vascular $[53,54]$. Además, poseen la GP VI y la integrina a $2 \beta 1$ 


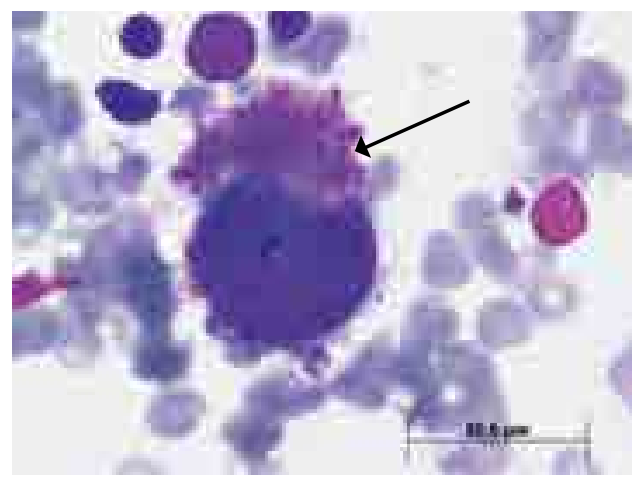

Figura 1. Megacariocito normal. Obsérvese (marcado con flecha) la producción de plaquetas. Coloración de Wright. 1000X. Cortesía Laboratorio Clínico Hematológico, Medellín, Colombia.

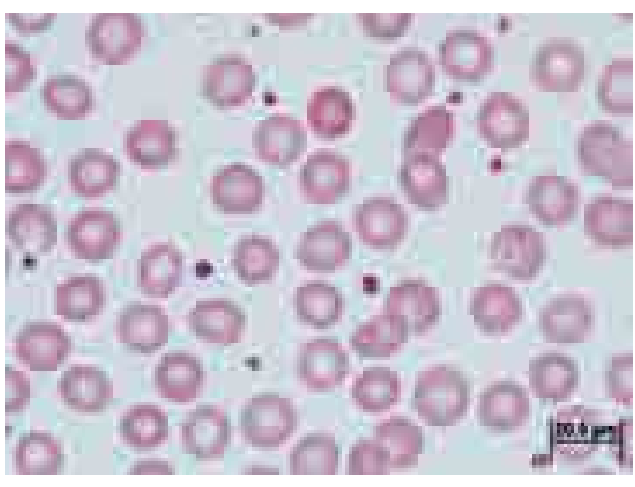

Figura 2. Extendido de sangre periférica. Se observan plaquetas en proporción y morfología normales. Coloración de Wright. 1000X. Cortesía Laboratorio Clínico Hematológico, Medellín, Colombia.

(GP Ia/IIa), dos receptores de adhesión al colágeno, que estabilizan la unión de la plaqueta al endotelio vascular. Tanto la GP Ib-IX-V y la GP VI activan el complejo GP IIb-IIIa (integrina aIIb $\beta 3$ ), también presente en la superficie plaquetaria, para que se una al fibrinógeno y la fibronectina en el sitio del daño subendotelial; proceso esencial para la agregación plaquetaria. Finalmente, la unión de la GP Ib-IX-V al factor von Willebrand desencadena la secreción de los productos que se mantienen en los gránulos de almacenamiento en las plaquetas $[53,55]$.

Además, las plaquetas presentan en su superficie receptores acoplados a proteínas $\mathrm{G}$, también conocidos como receptores transmembrana de siete dominios, que funcionan como receptores de agonistas que conducen a la activación plaquetaria. En este grupo se encuentran los receptores de trombina, el principal agonista plaquetario, conocidos como receptores activados por proteasa, PAR-1 y PAR-4, y los receptores de adenosín difosfato (ADP), un importante agonista plaquetario que también es secretado vía autocrina por los gránulos densos, entre los que se incluyen los receptores $P_{2} Y_{1}$ y $P_{2} Y_{12}$. El $P_{2} X_{1}$ es un receptor de adenosín trifosfato (ATP) que actúa también como canal de calcio, pero que pertenece a una familia de receptores diferente. Otro receptor acoplado a proteínas G importante a nivel plaquetario es el receptor de tromboxano, el TPa, que está acoplado a vías de señalización que activan la fosfolipasa $A_{2}$ y la fosfolipasa $C_{1}$ y el cual es importante para la amplificación autocrina de la activación plaquetaria después de la estimulación por los agonistas primarios [55].

Finalmente, las plaquetas en su interior contienen tres tipos principales de orgánulos secretores, incluyendo: a) gránulos alfa, que se encuentran en mayor cantidad y contienen el factor de coagulación $\mathrm{V}$, la trombospondina, la P-selectina, y el factor von Willebrand; además, proteínas sintetizadas en otras células que son captadas por las plaquetas, como el fibrinógeno, b) los cuerpos densos 
(gránulos delta), que son más pequeños y se encuentran en menor cantidad que los gránulos alfa y que son ricos en nucleótidos de adenina, incluyendo el ATP y el ADP, serotonina, pirofosfato, calcio y magnesio, y, c) lisosomas, que se encuentran en cantidad escasa y cuya función no ha sido totalmente esclarecida [53].

En la figura 3 se muestra una representación esquemática de la plaqueta en reposo.

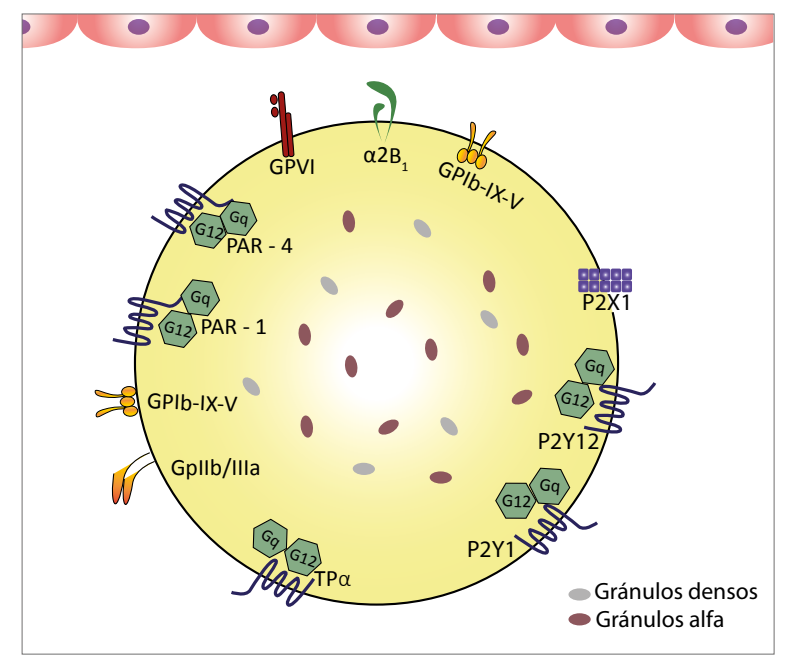

Figura 3. Representación esquemática de la plaqueta en reposo. Se presentan los principales receptores de superficie involucrados en los procesos de adhesión, activación y agregación plaquetaria y los gránulos secretores. Ver descripción en el texto.

\section{Fisiología de las plaquetas}

Las plaquetas desempeñan un papel fundamental en la hemostasia al iniciar la formación de coágulos o trombos, lo que fisiológicamente se conoce como hemostasia primaria. También participan en la reparación de vasos sanguíneos dañados.

En condiciones normales, las plaquetas permanecen en reposo, circulando a través de los vasos sanguíneos sin interactuar con otras células. Los diversos receptores en su superficie sirven para detectar aquellos cambios en el compartimento vascular (endotelio) que requieren de la respuesta hemostática de las plaquetas en los sitios de lesión del endotelio de la pared arterial debido a una herida o al rompimiento de la placa ateroesclerótica. Estos receptores son necesarios para la adhesión de las plaquetas a la superficie endotelial dañada, para desencadenar la activación completa de la plaqueta, para promover la agregación plaquetaria y la interacción con otros elementos celulares; además de acelerar el proceso de retracción del coágulo [53].

El proceso fisiológico de las plaquetas es complejo y dinámico e involucra tres fases conocidas como adhesión, activación y agregación, que se describirán a continuación. 


\section{Adhesión plaquetaria}

Cuando se detecta un daño en la pared de un vaso las plaquetas comienzan a adherirse al endotelio en cuestión de segundos [56]. Los catalizadores para esta interacción son los constituyentes expuestos del subendotelio, incluyendo el colágeno, el factor von Willebrand, la fibronectina, la laminina y la trombospondina, a los que se unen las plaquetas a través de sus receptores de superficie [57], lo que les permite no ser arrastradas por el torrente sanguíneo y mantener su adhesión en el sitio de la lesión.

El colágeno constituye el componente más trombogénico de la matriz extracelular del subendotelio, pero requiere del factor von Willebrand para estabilizar su interacción inicial con el receptor GP Ia/IIa (a2 31 ) y el GP VI de la plaqueta. Una vez que la plaqueta se ha enlazado, tanto con el colágeno como con el factor von Willebrand (a través del GP Ib-IX-V), cambia de forma discoidal a esférica [58]. Este cambio conformacional constituye la señal inicial que estimula cambios morfológicos sucesivos de la célula hasta adoptar una forma hemisférica, lo que incrementa el área de superficie de contacto con la pared arterial. Así, la adherencia de las plaquetas se hace más firme, pero esta adhesión aún es reversible. La adhesión irreversible se logra como resultado de otra cascada de señales que causan un extensivo aplanamiento de la plaqueta sobre el sitio dañado [58], dando origen a una segunda fase denominada activación plaquetaria.

En la figura 4 se muestra una representación esquemática de la adhesividad plaquetaria.

\section{Activación plaquetaria}

Es el proceso mediante el cual los cambios de forma de las plaquetas en reposo se convierten en una parte integral de la formación del coágulo. El enlace del colágeno y el factor von Willebrand a los receptores de la plaqueta desencadenan señales intracelulares mediadas por calcio. Esto trae aparejado la liberacón de los gránulos densos que almacenan sustancias activadoras de las plaquetas, por ejemplo, ADP y serotonina, la síntesis del tromboxano $A_{2}$, un activador plaquetario y vasoconstrictor, y un incremento de la población de receptores GP IIb/IIIa en la superficie de la plaqueta.

Al mismo tiempo, el tromboxano $A_{2}$, el ADP circulantes y otros agonistas solubles (p. ej. la alfa-trombina y la epinefrina) se enlazan, se adhieren a las plaquetas e inducen sinérgicamente su activación. Así, la activación plaquetaria es amplificada por varias vías de retroalimentación secundarias [59]. Específicamente, el ADP actúa sobre los receptores purinérgicos $P_{2} X_{1}$ y $P_{2} Y_{1}$, y el ATP sobre el $P_{2} Y_{12}$, desencadenando la activación plaquetaria de forma sinérgica. El receptor P2X1 participa en el cambio de la forma de la plaqueta previamente descrita, el P2Y1 es 


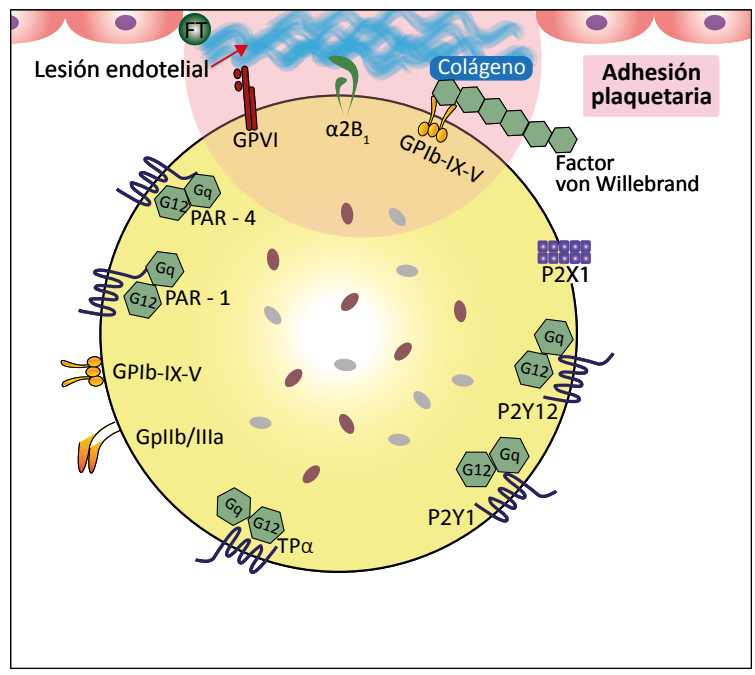

Figura 4. Adhesividad plaquetaria. Durante las lesiones del endotelio vascular se exponen elementos de la matriz extracelular subendotelial como el colágeno y el factor de von Willebrand. En respuesta, las plaquetas se adhieren al endotelio vascular en el sitio de la lesión mediante los receptores de superficie plaquetarios GP Ib-IX-V y GP VI que se unen al colágeno y la estabilización de la interacción inicial mediada por la unión del GP Ia/IIa (integrina a2 $\beta 1$ ) al factor de von Willebrand. Ver descripción en el texto.

responsable de la activación reversible inicial y el $\mathrm{P}_{2} \mathrm{Y}_{12}$ de la activación prolongada y la posterior agregación de las plaquetas [60].

Durante este proceso también se induce la formación del ácido araquidónico a partir de los fosfolípidos de la membrana celular a través de la acción de la fosfolipasa $A_{2}\left(P_{2} A_{2}\right)$ citoplasmática. El ácido araquidónico es metabolizado por la enzima ciclooxigenasa-1 (COX-1), principalmente en las prostaglandinas G2/ H2 (PGG2/PGH2) y, posteriormente, a tromboxano $A_{2}$ por acción de la enzima tromboxano $A_{2}$ sintetasa. El tromboxano $A_{2}$ activa las plaquetas e induce posteriormente su agregación por la interacción con el receptor TPa, mientras que ejerce un efecto proinflamatorio en las células de la pared arterial $[60,61]$.

Otro paso importante en la activación de las plaquetas es la exposición de los componentes de los fosfolípidos de la membrana de la superficie de la plaqueta cargados negativamente, que desencadena la bien conocida cascada de la coagulación clásica, iniciada por la exposición intravascular del factor tisular, que al final resulta en la generación de fibrina insoluble que provee una estabilización de los enlaces cruzados entre las plaquetas adyacentes [62]. Las interacciones entre las plaquetas activadas, sumada a la secreción de los cofactores de la coagulación, por ejemplo el factor $V$ (factor tisular) de la coagulación, y sus enzimas asociadas maximizan la generación de trombina, la cual es un potente estimulante de la activación plaquetaria mediante la interacción con sus receptores, el PAR-1 y el PAR-4, y también sobre el complejo GP Ib-IX-V.

En la figura 5 se muestra una representación esquemática de la activación plaquetaria. 
Figura 5. Activación plaquetaria. La adhesión de las plaquetas activa diferentes cascadas intracelulares mediadas por calcio que llevan a: 1) La secreción de ADP y ATP de los gránulos alfa, que actúan sobre los receptores purinérgicos $\mathrm{P}_{2} \mathrm{X}_{1}$ y $\mathrm{P}_{2} \mathrm{Y}_{1}$, y $\mathrm{P}_{2} \mathrm{Y}_{12}$, respectivamente, induciendo de forma sinérgica la activación plaquetaria y participando en el cambio de la forma redondeada de la plaqueta a la forma estrellada. 2) La síntesis de ácido araquidónico (AA) a partir de los fosfolípidos de la membrana celular mediante la acción de la enzima fosfolipasa $A_{2}$ (PLA2) citoplasmática, el cual es metabolizado por la COX-1 en prostaglandinas $\mathrm{G} 2 / \mathrm{H} 2$ (PGG2/PGH2) y, posteriormente, a tromboxano $A_{2}\left(T \times A_{2}\right)$ por acción de la enzima $T \times A_{2}$ sintetasa (Tx sintasa). 3) La secreción del TxA que se une al receptor TPa en la superficie plaquetaria para amplificar la activación plaquetaria después del estímulo inducido por los agonistas primarios. 4)

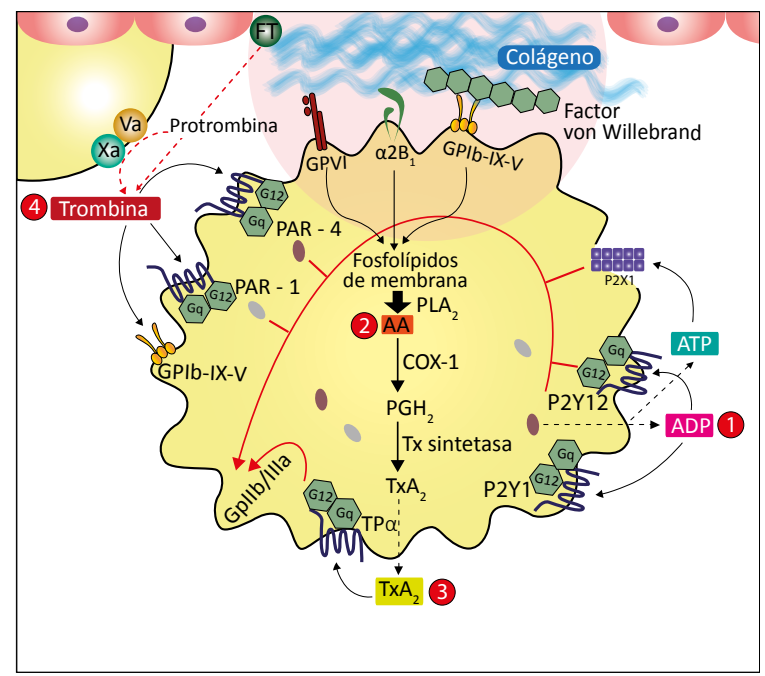

La síntesis maximizada de trombina, que fue iniciada por la exposición intravascular del factor tisular (FT), por el complejo protrombinasa (formado por el factor Xa y el factor Va) en la superficie de las plaquetas activadas, convirtiendo grandes cantidades de protrombina en trombina durante la cascada de coagulación. La trombina se une a los receptores PAR-1 y PAR-4, actuando como uno de los activadores plaquetarios más potentes. Ver descripción en el texto.

\section{Agregación plaquetaria}

La última fase de la activación de las plaquetas se conoce con el nombre de agregación plaquetaria, la cual se entrelaza con los últimos estados de la cascada de la coagulación y se solapa de algún modo con la fase de activación de las plaquetas. La agregación está fundamentalmente mediada por los receptores GP IIb/IIIa de la superficie de las plaquetas que enlazan varias proteínas de adhesión. Esos receptores tienen una baja afinidad por sus ligandos bajo condiciones de reposo, pero durante la activación de las plaquetas se activan. El fibrinógeno, producido por el hígado y almacenado en los gránulos alfa de las plaquetas, se secreta durante la activación plaquetaria y constituye una de las moléculas de adhesión más importantes que se enlaza a los receptores GP IIb/IIIa, uniendo las plaquetas entre sí.

Debido a que la activación de las plaquetas incrementa la densidad de los receptores en la superficie, se puede enlazar más fibrinógeno, con lo que se alcanza una elevada concentración que permite la conversión a fibrina mediada por trombina. Concomitantemente, los receptores GP IIb/IIIa sobre la superficie de las plaquetas inmovilizan otras proteínas solubles de adhesión, tales como el factor von Willebrand, la fibronectina y la vitronectina. El conjunto de estos procesos atrae más plaquetas al sitio del daño y el enlace de fibrinógeno estimula el enlace cruzado de la fibrina con nuevas plaquetas. La fibrina fortalece la estructura, permitiendo que continúe la agregación plaquetaria, la formación del trombo plaquetario y su crecimiento $[52,56]$. 
En la figura 6 se muestra una representación esquemática de la agregación plaquetaria y en la figura 7 un esquema de la formación del trombo plaquetario.
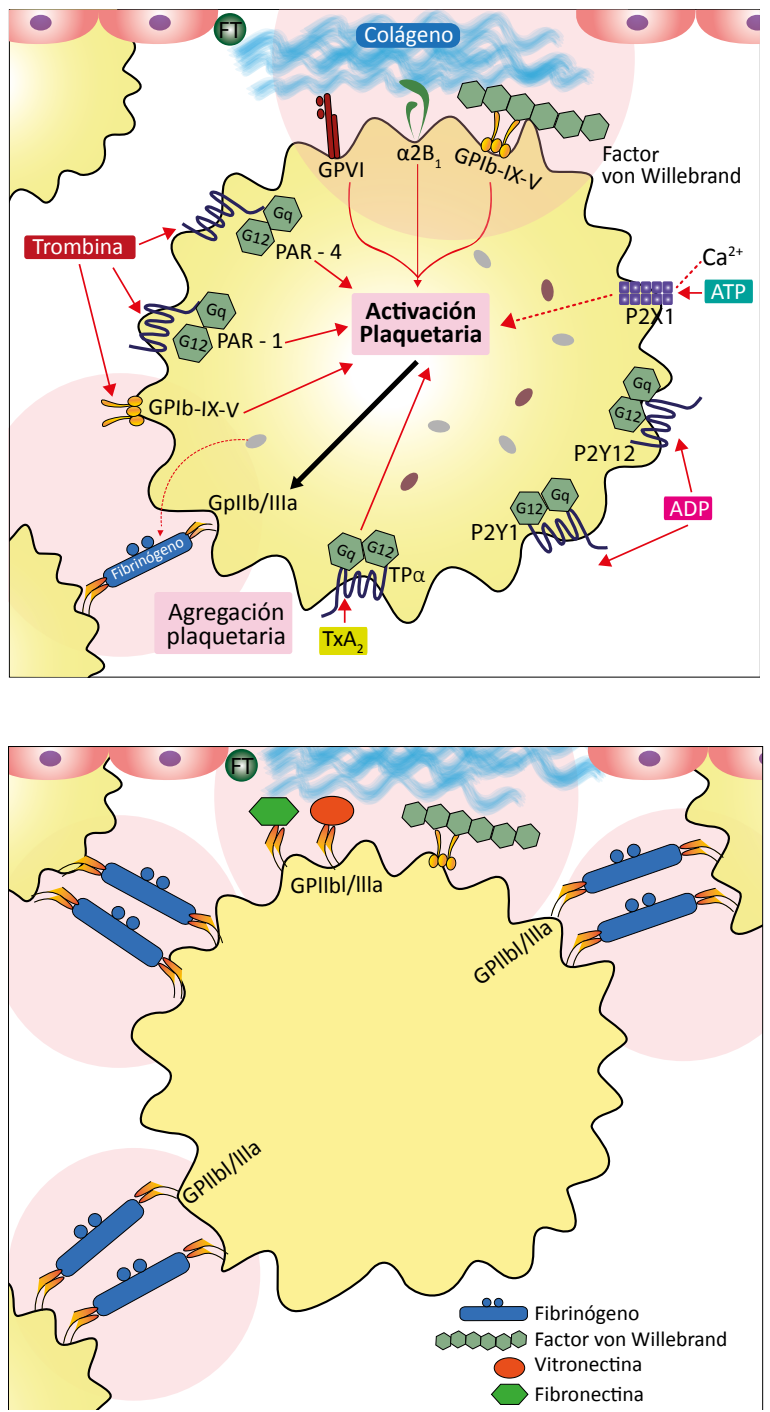

Figura 6. Agregación plaquetaria. Las plaquetas activadas por las diferentes vías descritas se unen entre sí a través de puentes de fibrinógeno fijados a la integrina aIIbß3 (GP IIb/IIIa) presente en la superficie plaquetaria. Ver descripción en el texto.

Figura 7. Formación del trombo plaquetario. La agregación plaquetaria conduce finalmente a la formación del trombo plaquetario, que en condiciones fisiológicas conduce al control de la lesión endotelial, pero en otras condiciones puede ser responsable de condiciones patológicas como los accidentes cerebrovasculares y la ateroesclerosis. Ver descripción en el texto.

\section{La aspirina como antiagregante plaquetario}

\section{Farmacocinética de la aspirina}

Tras la administración oral de la aspirina esta se absorbe rápidamente a partir del estómago y de la primera porción del intestino delgado (duodeno) [51], obteniendo concentraciones plasmáticas apreciables a los 20-30 minutos y máximas a los 60-120 minutos $[63,64]$. La tasa de absorción depende de diversos factores, 
entre los cuales destacan la velocidad de desintegración y disolución, que varían según la forma galénica, el $\mathrm{pH}$ gástrico e intestinal, la velocidad de vaciamiento gástrico y la presencia de alimentos en el tracto digestivo. La mayoría de la aspirina que llega a la sangre se combina con la albúmina y solo una pequeña proporción permanece libre para desempeñar un papel fisiológico .

La vida media de la aspirina (ácido acetilsalicílico) es muy corta, de 15 a 20 minutos [64], siendo la gran mayoría de este metabolizado a nivel del hígado a ácido salicilúrico, ácido salicílico y glucorónidos fenólicos, mientras que una pequeña proporción del medicamento es metabolizada a ácido gentísico [65]. Los metabolitos resultantes de la degradación de la aspirina tienen una vida más prolongada, de 3 a 6 horas y son excretados principalmente a nivel de los riñones y la alcalinización de la orina puede aumentar esta excreción [66]. La dosis mínima requerida para alcanzar el efecto antiagregante de la aspirina, esto es, para suprimir la formación de tromboxano $A_{2}$, es de $0,45 \mathrm{mg} / \mathrm{kg}$, lo que en la práctica en un adulto promedio representa tan solo una dosis de $30 \mathrm{mg}$ diarios de aspirina para lograr el efecto deseado.

\section{Mecanismo de acción \\ de la aspirina como antiagregante plaquetario}

La acción antiplaquetaria de la aspirina se atribuye principalmente a la inhibición irreversible de la actividad de la ciclooxigenasa-1 por acetilación de un residuo de serina en la posición 529 (Ser529) de la cadena polipeptídica de la enzima donde se encuentra su sitio activo $[67,68]$. De esta forma se interrumpe la transformación del ácido araquidónico en sus derivados ciclooxigénados, así como los mecanismos fisiopatológicos en los que éstos están implicados, reduciéndose como resultado final la inhibición de la producción de tromboxano $A_{2}$ por las plaquetas [68-72]. La acción de la aspirina también se presenta sobre los megacariocitos, las células precursoras de las plaquetas [73]. Debido a que las plaquetas son células anucleadas y, por tanto, incapaces de llevar a cabo la síntesis proteica, no pueden reponer la actividad enzimática, por lo que la inhibición enzimática es irreversible y se prolonga durante toda la vida de la plaqueta, esto es de 7 a 10 días $[69,74,75]$.

En la figura 8 se esquematiza el mecanismo por medio del cual la aspirina actúa como un antiagregante plaquetario.

\section{Resistencia a la aspirina}

\section{Definición de la resistencia a la aspirina}

Los términos «resistencia a la aspirina», «no respondedores a la aspirina» o «falta de respuesta a la aspirina», que se utilizan indistintamente, aún no constituyen 
una definición aceptada universalmente [76-78]. Desde el punto de vista práctico, la resistencia a la aspirina se define de acuerdo con dos criterios:

- Resistencia a la aspirina in vivo, también denominada resistencia clínica, como la incapacidad de la aspirina para evitar eventos clínicos aterotrombóticos, a pesar de que el paciente esté tomando la aspirina regularmente a la dosis indicada [76-78]; y

- Resistencia a la aspirina in vitro, también denominada resistencia de laboratorio, como la incapacidad de la aspirina, demostrado por pruebas de laboratorio, para inhibir total o parcialmente la agregación plaquetaria [76, 78-97].

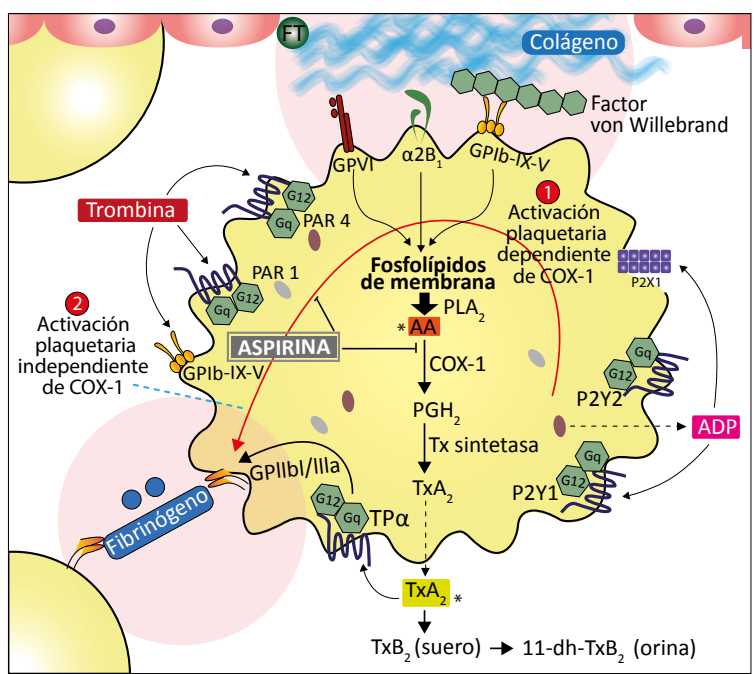

Figura 8. Mecanismo de acción de la aspirina como antiagregante plaquetario. En condiciones normales agonistas como la trombina, el ADP, el colágeno y la epinefrina activan las plaquetas, provocando la agregación plaquetaria por vías dependiente e independiente de la actividad de la enzima COX-1. Una vez en la circulación, la aspirina actúa sobre la enzima COX-1 plaquetaria, bloqueando la síntesis de la PGH2 a partir del ácido araquidónico (AA) y la subsecuente generación del TxA $A_{2}$. De esta manera, la activación plaquetaria y el efecto proagregativo inducido por el $\mathrm{TxA}_{2}$ es inhibida. Es importante resaltar que el $\mathrm{TxA}_{2}$ es inestable en solución acuosa, por lo que es rápidamente hidrolizado a tromboxano $\mathrm{B}_{2}\left(\mathrm{Tx}_{2}\right)$, un producto más estable pero fisiológicamente inactivo, que se puede encontrar en el suero. Algunos de sus metabolitos, como el 11-dehidrotromboxano $B_{2}\left(11 d h T \times B_{2}\right.$ ) se encuentra

en la orina, cuyos niveles reflejan la producción acumulativa de $\mathrm{TxA}_{2}$ in vivo y, en este sentido, la actividad de la aspirina. Ver descripción en el texto.

\section{Prevalencia de la resistencia a la aspirina}

La prevalencia de la resistencia a la aspirina, diagnosticada por métodos de laboratorio, tiene un amplio rango que varía desde porcentajes tan bajos como el 0,4\% [98] a tan altos como el 56,8\% [99], explicable en gran parte en función de la definición, los métodos utilizados, la población estudiada y las comorbilidades de los pacientes estudiados, entre otras circunstancias [76, 82-85, 87].

Tratando de encontrar la verdad en relación con la prevalencia de la resistencia a la aspirina, Hovens y colaboradores (2007), tras una revisión sistemática que incluyó 34 estudios y 8 reuniones, determinada por métodos solos o combinados de agronometría óptica, PFA- $100{ }^{\circledR}$ y VerifyNow ${ }^{\circledR}$, encontraron una prevalencia media de resistencia a la aspirina del 24\% (intervalo de confianza del $95 \%$ : 20\% al 28\%) 
[90], es decir, que uno de cada cuatro pacientes es susceptible de ser resistente al tratamiento. Estos valores son muy similares a los que han informado otros investigadores [80, 100-118] [119-127].

En nuestro medio, de acuerdo un estudio realizado en Medellín y en Bogotá, en pacientes con enfermedad coronaria, se encontró que la resistencia a la aspirina, a dosis bajas (80-325 mg/día), determinada por agregación plaquetaria con ácido araquidónico es de 28,2\% (CI 95\%: 18,1\%-40,1\%), una buena razón para la medición rutinaria de la actividad plaquetaria en estos pacientes [128]. Más adelante se analizará la experiencia local.

\section{Implicaciones clínicas de la resistencia a la aspirina}

Para tener una mejor idea de las implicaciones clínicas de la resistencia a la aspirina es necesario conocer la importancia de la aspirina como antiagregante plaquetario, como se analizará a continuación.

\section{Aspirina y enfermedades cardiovasculares}

Sin duda alguna, en donde más se ha utilizado la aspirina a bajas dosis ha sido en la prevención primaria y secundaria de las enfermedades cardiovasculares.

\section{Aspirina en la prevención primaria de las enfermedades cardiovasculares}

En la prevención primaria, definida por la OMS como las medidas encaminadas a evitar la aparición de una enfermedad en personas sanas, en el caso de las enfermedades cardiovasculares el uso de aspirina en pacientes sin historia de enfermedad cardiovascular manifiesta, pero con factores de riesgo como la obesidad, la dislipidemia, la hipertensión arterial, la diabetes y el tabaquismo, entre otros, ha demostrado ser eficiente para reducir la posibilidad de un infarto agudo de miocardio en un $17 \%$ y la aparición de un accidente cerebrovascular isquémico en un $14 \%$ [128, 129]. También es claro que la aspirina no está indicada en la prevención primaria en población sin factores de riesgo cardiovascular $[128,129]$.

\section{Aspirina en la prevención secundaria de las enfermedades cardiovasculares}

En la prevención secundaria, definida por la OMS como las medidas encaminadas al tratamiento y a la rehabilitación de una enfermedad para retardar su progresión y con ello la aparición o el agravamiento de complicaciones e invalideces e intentando mejorar la calidad de vida de los pacientes, los antiagregantes plaquetarios, en particular la aspirina, usualmente asociada con clopidogrel u otros antiagregantes, han demostrado ser el eje central para el buen manejo de estos pacientes. A partir de los múltiples trabajos que se han desarrollado alrededor de 
este tema, el uso de la aspirina, usualmente asociada con otros antiagregantes plaquetarios, ha demostrado su eficacia en la prevención secundaria en pacientes que han sufrido uno o varios accidentes trombóticos o con patología cardiovascular incluyendo pacientes con angina de pecho, angina inestable, infarto agudo de miocardio, infarto cerebral y accidente isquémico transitorio [130-134]. Además, se ha demostrado que la resistencia a la aspirina puede aumentar, en diez veces, el riesgo de infarto del miocardio y de ictus isquémico a dos años [101], en 3,5 veces, el riesgo de muerte con relación a la población de pacientes bajo prevención secundaria libres de resistencia a la aspirina [135], en 3,1 veces, el riesgo de un infarto de miocardio, el ictus isquémico y la muerte, a 1,8 años, en pacientes con enfermedad coronaria crónica [136], entre otros muchos desenlaces de las diferentes manifestaciones de la arterioesclerosis.

\section{Aspirina en las enfermedades cerebrovasculares}

El ictus isquémico, también conocido como trombosis isquémica y apoplejía, se ubica entre las tres primeras causas de mortalidad, la primera causa de discapacidad resultante y la segunda de demencia en sujetos de edad media y avanzada, con una tasa anual creciente como resultado del aumento de las expectativas de vida y las mejoras en los servicios de salud, que favorece que los pacientes sobrevivan a la presentación del primer evento [137], representando enormes costos para los sistemas de salud [138]. La posibilidad de recurrencia a un año de haber sufrido el primer ictus isquémico es del $12 \%$ y después de los cinco años de un $30 \%$ [139-142]. Además de lo anterior, la historia de un ictus isquémico previo aumenta significativamente la posibilidad de morir por un accidente cardiovascular a partir del tercer año posevento [140, 141, 143]. Como en el caso de la prevención primaria en las enfermedades cardiovasculares, la aspirina en la prevención primaria de las enfermedades trombóticas cerebrales no estaría indicada a no ser que el paciente presente factores de riesgo que serían los mismos que para las enfermedades cardiovasculares.

Es claro que el tratamiento antiagregante plaquetario constituye el tratamiento farmacológico de elección en la prevención secundaria del ictus isquémico [144] y la resistencia a los antiagregantes puede ser responsable de desenlaces fatales [145-149], motivo más para hacer el control de la antiagregación con la ayuda de pruebas de laboratorio como las que se analizan en este módulo.

\section{Aspirina en obstetricia}

El uso de la aspirina se introdujo en la práctica de la ginecoobstetricia a partir de 1978 cuando por primera vez se indicó en el tratamiento de la toxemia recurrente [150]. A partir de esta primera publicación se ha venido consolidando su uso en la prevención y el manejo de la preeclampsia y el retardo del crecimiento intrauterino. Además, la aspirina ha venido posicionándose en el manejo de las pacientes 
con pérdidas fetales recurrentes asociadas con trombofilia, en particular las de tipo trombopático, como se analizará en los dos siguientes subtítulos.

\section{Aspirina y preeclampsia e hipertensión gestacional}

La preeclampsia, un desorden multisistémico especifico del embarazo y el puerperio, que remite después del parto, no es una simple enfermedad: es un síndrome que comprende tres elementos a saber hipertensión arterial en mujeres normotensas previas al embarazo, proteinuria (> $300 \mathrm{mg} /$ en orina de 24 horas) y edema que se presenta a partir de la semana 20 de gestación [151]. La preeclampsia es un grave problema de salud pública con enormes costos sociales y económicos, tanto para la población como para los sistemas de salud, teniendo en cuenta que es una complicación que se manifiesta entre el $2 \%$ y el $8 \%$ de los embarazos y representa del $10 \%$ al $15 \%$ de las muertes maternas [152]. La etiopatología de la preeclampsia no está totalmente establecida. Se ha demostrado una producción intravascular deficiente del vasodilatador prostaciclina, con producción excesiva de tromboxano $\mathrm{A}_{2}$ [153]. Estas observaciones han llevado a la hipótesis de que los agentes antiplaquetarios, y particularmente la aspirina a dosis bajas, pueden prevenir o retrasar el desarrollo de la preeclampsia y sus nefastas consecuencias [154-163].

En mujeres embarazadas de alto riesgo, se ha encontrado que las bajas dosis de aspirina reducen el riesgo de preclamsia en un $10 \%$ y la restricción del crecimiento fetal en un $20 \%$ [160, 164]; no obstante, una proporción significativas de las pacientes que reciben aspirina a las dosis recomendadas tiene una respuesta subóptima, definida bioquímicamente como una disminución en la actividad supresora/antiagregante de la actividad plaquetaria o clínicamente con el desarrollo de eventos trombóticos a pesar de estar bajo tratamiento con bajas dosis de aspirina $[78,154,165]$; situación que se conoce como resistencia a la aspirina como ya se ha mencionado.

\section{Aspirina y pérdidas fetales}

Las trombofilias, definidas como la tendencia a desarrollar fenómenos de trombosis arterial o venosa recurrente, espontáneas o con mínima provocación, a edades menores de las habituales, en territorios poco comunes ya sea de origen congénito o adquirido $[166,167]$, en los últimos años se han documentado como causa íntima de pérdidas fatales recurrentes [168-172]. Dentro las trombofilias congénitas asociadas con pérdidas fetales recurrentes la que más se ha encontrado en nuestro medio [173, 174] y en otros países latinoamericanos [175-177] es el síndrome de plaqueta pegajosa situación que se controla efectivamente con aspirina a bajas dosis. Como en todos los casos anteriores, en estas pacientes el tratamiento con aspirina puede presentar resistencia y por lo tanto no ser suficiente para el manejo de la perdida fetal, de ahí la importancia del seguimiento a través de pruebas de laboratorio, como las analizadas en este módulo. 


\section{Etiología de la resistencia a la aspirina}

La causa íntima de la resistencia de aspirina no está lo suficientemente aclarada, a pesar de que se han propuesto múltiples mecanismos que van desde factores demográficos hasta la taquifilaxia, pasando por factores, tan diversos, como la biodisponibilidad de la aspirina, los estados de hiperactividad plaquetaria, los polimorfismo plaquetarios y las comorbilidades que pueda presentar el paciente, como se analizará en los siguientes subtítulos.

\section{Factores demográficos}

Entre estos factores se ha descrito una tendencia mayor a presentarse resistencia a la aspirina en el sexo femenino $[108,110,112,178,179]$ que en el sexo masculino y en pacientes con edad avanzada $[110,112,180]$ que en los jóvenes; este último factor, posiblemente relacionado con aumento de las comorbilidades o la ateroesclerosis y con taquifilaxia.

\section{Biodisponibilidad de la aspirina}

Posiblemente esta sea la causa más frecuente de la resistencia a la aspirina. En este sentido se presentan varias posibilidades para su presentación. Inicialmente, no tomar la medicación a las dosis y condiciones indicadas [181-183], esto es, cada 24 horas, a una dosis entre $81 \mathrm{mg}$ y $325 \mathrm{mg}$, debido a que si no lo hace religiosamente, día a día, en la circulación sanguínea habrá una proporción importante de plaquetas «no aspirinizadas», producto de la trombopoyesis realizada en el período en el cual no se ha tomado la droga, plaquetas que son hemostáticamente activas, máxime cuando son plaquetas jóvenes. Otra situación, relativamente frecuente, es utilizar la presentación de la aspirina con capa entérica, debido a que con esta formulación el pico máximo en la sangre aparece entre 3 y 4 horas después de haber ingerido la droga [184], en contraposición de menos de una hora que se logra con la aspirina sin esta cubierta [68]. Otras circunstancias asociadas con resistencia a la aspirina por falta de su biodisponibilidad se relacionan con el consumo concomitante con otros medicamentos, en particular con los antiinflamatorios no esteroideos (AINEs) [185, 186], incluidos el ibuprofeno [187], la indometacina y el naproxeno, debido a que compiten con la aspirina por los sitios de unión a la COX-1 [185, 188, 189] y los inhibidores de la bomba de protones [78, 184, 190-193], por una mayor acción de las estearasas de la mucosa gástrica sobre la aspirina que podrían reducir la absorción de la droga [78], entre otros.

\section{Hiperactividad plaquetaria}

En la comunidad científica se conoce que hay una serie de situaciones clínicas caracterizadas por presentar hiperactividad plaquetaria; mecanismo a través del cual se podría explicar la mayor prevalencia de resistencia a la aspirina en pacientes con enfermedades cardiovasculares, en los que hay una mayor posibilidad de 
daño endotelial, incluidas, entre otras, la cardiopatía isquémica [194, 195], la insuficiencia cardíaca congestiva [99], la hipertensión arterial [194] y los síndromes coronarios agudos acompañados de neumonía (respecto a aquellos sin complicaciones respiratorias) [196]. Además, en pacientes con enfermedades metabólicas como la dislipidemia y la obesidad [99, 194, 195], el síndrome metabólico [197, 198] y la diabetes mellitus tipo 1 y tipo 2 [199]. También se incluyen el estrés y el ejercicio extremo debido a que producen un aumento en la activación plaquetaria y como consecuencia disminución a la antiagregación con aspirina [200, 201].

Otras situaciones de resistencia a la aspirina debido a mecanismos relacionados con hiperactividad plaquetaria son la interacción plaquetaria con otras células sanguíneas y los productos derivados de ellas, como el bloqueo inadecuado de la función plaquetaria inducida por eritrocitos [202], las alteraciones en el metabolismo del ácido araquidónico trascelular entre las plaquetas y las células vasculares (endotelio) [203], las alteraciones del tromboxano $A_{2}$ derivado del monocito-macrófago [204-206] y de la prostaciclina (PGI2) vascular, catalizador de la COX-1/COX-2 y que actúa como regulador del tromboxano $A_{2}$ plaquetario [207], o del activador tisular del plasminógeno [208] y el aumento de la noradrenalina, por ejemplo, por ejercicio excesivo y estrés [209, 210]. También se incluyen la agregación eritrocitaria elevada [211], los síndromes de hiperagregabilidad plaquetaria como los que se presentan en la trombocitosis primaria [212, 213] y la trombocitosis secundaria, los síndromes mielodisplásicos y el síndrome de plaqueta pegajosa [174]. Además, el recambio plaquetario acelerado que introduce al torrente sanguíneo nuevas plaquetas «no-aspirinizadas» [214] y las transfusiones plaquetarias, en las que ingresan al torrente sanguíneo nuevas plaquetas no aspirinizadas procedentes del donante. Igualmente, por este mecanismo se puede explicar algún grado de resistencia a la aspirina en pacientes fumadores crónicos [215-220], con estrés oxidativo y biosíntesis de la 8-iso-prostaglandina F2-a, un producto bioactivo de la peroxidación no enzimática del ácido araquidónico [216, 221-223] y la interacción de la aspirina con el efecto antiplaquetario y vasodilatador de la acetilcolina mediado por el ácido araquidónico [224, 225].

\section{Polimorfismos y mutaciones genéticas}

Son múltiples los mecanismos farmacodinámicos que pueden llevar a que la aspirina no alcance su objetivo como antiagregante plaquetario. De estos los más importantes, son el polimorfismo de COX-1, COX-2, tromboxano $A_{2}$ sintetasa, $u$ otras enzimas del metabolismo del ácido araquidónico [226-228], el polimorfismo de las proteínas plaquetarias IIb/IIIa, de los alelos PIA2 [229-231], el polimorfismo del receptor plaquetario al colágeno [232] y el polimorfismo del receptor del factor XIII de la coagulación, val34leu, que lleva a una inhibición variables de la activación del factor XIII con dosis bajas de aspirina [233, 234]. 


\section{Taquifilaxia}

Finalmente, se invoca, como causa de la resistencia a la aspirina, la taquifilaxia, definida como una disminución gradual del efecto de un fármaco al ser administrado en forma continua o repetida, que se expresa como una reducción de la respuesta farmacológica esperada [235]. Con relación a la pérdida de la eficacia farmacológica de la aspirina, se conoce que aunque la supresión completa de la COX-1 plaquetaria por la aspirina se mantiene en los controles sanos durante los primeros meses [236], la pérdida de la supresión de la agregación plaquetaria inducida por el agonista se ha informado durante largo plazo (meses o años) de tratamiento [80, 237]. Esta observación es consistente con una mayor incidencia de eventos cardiovasculares adversos en los usuarios de aspirina anteriores [238, 239].

El mecanismo por el cual el tratamiento con aspirina podría perder parte de su efecto antiplaquetario durante la administración a largo plazo es desconocida, pero se podría explicar por la progresión de la aterosclerosis o la reducción progresiva de la actividad farmacológica de acuerdo con el tiempo [240]. La taquifilaxia se puede explicar por múltiples causas, tales como alteraciones moleculares en la estructura de los receptores, disminución del número de receptores en la superficie celular, agotamiento de los mediadores endógenos, aumento de la degradación metabólica del fármaco, adaptación fisiológica que suprime algunos efectos del fármaco y expulsión activa del fármaco del interior de las células [235].

En la tabla 1, a manera de resumen, se agrupan los posibles mecanismos de la resistencia a la aspirina informados en la literatura médica mundial.

\section{Seguimiento del paciente con antiagregación plaquetaria con aspirina y diagnóstico de la resistencia a la aspirina}

A la hora de establecer el diagnóstico de la resistencia a la aspirina se debe tener claridad si se está haciendo referencia a una resistencia clínica o bien a una resistencia basada en pruebas de laboratorio como se mencionó en el subtítulo de la definición de la resistencia a la aspirina. En cuanto al diagnóstico clínico este solo es posible establecerlo cuando ha sucedido un evento aterotrombótico, ya sea de localización cardiovascular, cerebrovascular u otro sitio del lecho vascular, en un paciente tomando regularmente una dosis terapéutica de aspirina [76-78]. Por otro lado, el diagnóstico de laboratorio de la resistencia a la aspirina se basa en estudios de laboratorio que evidencian el bloqueo de la síntesis de tromboxano $\mathrm{A}_{2}$, o sus metabolitos en sangre u orina, o bien observando la función plaquetaria dependiente del tromboxano [78]. El diagnóstico de la resistencia a la aspirina se debe establecer de acuerdo con resultados de pruebas de laboratorio, estandarizadas, creíbles, clínicamente relevantes y que se correlacionen con la realidad clínica del paciente [78]. 


\section{Tabla 1. Posibles mecanismos de resistencia a la aspirina informados en la literatura médica mundial}

Factores demográficos

Sexo femenino $[108,110,112,170,171]$

Edad avanzada [110, 112, 172]

Biodisponibilidad de la aspirina

Consumo a las dosis y en las condiciones inadecuadas [173-175]

Uso de aspirina con capa entérica [176]

Consumo concomitante con otros medicamentos (p. ej. antiinflamatorios no esteroideos (AINEs) [177, 178], ibuprofeno [179], indometacina, naproxeno [177, 180, 181], inhibidores de la bomba de protones $[78,176,182-185])$

\section{Hiperactividad plaquetaria}

Enfermedades cardiovasculares activas (p. ej. cardiopatía isquémica [186, 187], insuficiencia cardíaca congestiva [99], hipertensión arterial [186], síndromes coronarios agudos acompañados de neumonía [188])

Enfermedades metabólicas (p. ej. dislipidemia y obesidad [99, 186, 187], síndrome metabólico [189, 190], diabetes mellitus tipo 1 y tipo 2 [191])

Estrés y ejercicio extremo [192,193].

Interacción plaquetaria con otras células sanguíneas y productos derivados de ellas (p. ej. bloqueo inadecuado de la función plaquetaria inducida eritrocitos [194], alteraciones en el metabolismo de ácido araquidónico trascelular entre las plaquetas y las células vasculares (endotelio) [195], del tromboxano A2 derivado del monocito-macrófago [196-198] y del PGI2 vascular como catalizador de COX-1/COX-2 que actúa como regulador del tromboxano A2 plaquetario [199] o del activador tisular del plasminógeno [200] y aumento de noradrenalina, por ejemplo, con ejercicio excesivo y estrés [201, 202])

Agregación eritrocitaria elevada [203]

Síndromes de hiperagregabilidad plaquetaria (trombocitosis primaria y secundaria [bibliografías], síndromes mielodisplásicos [bibliografías], síndrome de plaqueta pegajosa [166])

Recambio plaquetario acelerado[206]

Transfusiones plaquetarias [bibliografías]

Tabaquismo [207-212]

Estrés oxidativo y biosíntesis de 8-iso-PGF2-a [208, 213-215]

Interacción de la aspirina con la acetilcolina mediado por el ácido araquidónico [216, 217]

Polimorfismos y mutaciones genéticas

Polimorfismo de las enzimas COX-1, COX-2, tromboxano A2 sintetasa, u otras enzimas involucradas en el metabolismo del ácido araquidónico [218-220]

Polimorfismo de las proteínas plaquetarias GbIIb/IIIa, de los alelos PIA2 [221-223]

Polimorfismo del receptor plaquetario al colágeno [224]

Polimorfismo del receptor del factor XIII de la coagulación, val34leu [225, 226]

Taquifilaxia

Taquifilaxia $[80,227-232]$

Como se ha expresado, para el control de la antiagregación plaquetaria con aspirina y la detección de la resistencia a la aspirina, desde el punto de vista del laboratorio clínico, se dispone de métodos bioquímicos y de métodos funcionales, como se analizará a continuación.

Medicina \& Laboratorio / Volumen 22, Números |-2, 2016. 


\section{Métodos bioquímicos}

Los métodos bioquímicos para medir la actividad antiagregante de la aspirina se fundamentan en la determinación de metabolitos, productos finales del ciclo del ácido araquidónico, que reflejan el nivel de la actividad plaquetaria [241, 242]. Tras la administración de aspirina a bajas dosis se reduce la producción y excreción de los metabolitos del ácido araquidónico, el tromboxano $B_{2}$ en suero [243] $y$ el 11-dehidrotromboxano $B_{2}$ en orina. En el caso de resistencia a la aspirina se observan niveles normales de tromboxano $B_{2}$ y de 11-dehidrotromboxano $B_{2}$, como se observa en pacientes que han sufrido eventos vasculares [244], similares o cercanos a los controles que no están bajo el efecto de aspirina.

Actualmente en el país no se disponen de pruebas bioquímicas para el estudio de la resistencia a la aspirina. En el futuro inmediato, su introducción dependerá de la necesidad manifiesta de los clínicos para que los laboratorios clínicos las provean.

\section{Métodos funcionales}

Se refieren a los métodos que miden la alteración (trombocitopatía) producida por el fármaco administrado. De todas las pruebas disponibles en el laboratorio clínico, particularmente en algunos especializados en este tipo de estudios, el médico dispone de varias alternativas, como se analizará a continuación, en donde solo se revisaran los que estén disponibles en el medio.

\section{Tiempo de sangría}

El tiempo de sangría fue descrito en 1910 [245]; desde entonces y hasta 1963, cuando se inventó la agregometría plaquetaria [246], fue la única prueba disponible para evaluar la función de las plaquetas, incluso llegó a ser considerado como el «estándar de referencia ». Hoy, el tiempo de sangría se ha incluido en el grupo de las pruebas obsoletas, que los laboratorios clínicos no deberían continuar ofertando y realizando [247]. El tiempo de sangría es una prueba invasiva, en la que el paciente recibe un corte en la piel, pero lo más grave es que no es lo suficientemente sensible y específica para el estudio de la función plaquetaria, como claramente lo demostraron los estudios del Colegio Americano de Patología Clínica (CAP) y la Sociedad Americana de Patología Clínica (ASCP), razón por la cual lo desaconsejan [248] y, es así como, aunque en la mayoría de los laboratorios clínicos se continua realizando, ha desaparecido de los textos de hematología [249] y de coagulación [250], para dar paso a pruebas de utilidad clínica y mejor desempeño analítico, como las que se analizarán a continuación.

\section{Agregación plaquetaria}

La introducción de la agregación plaquetaria por transmisión de luz [246], también denominada agregometría óptica, introdujo al laboratorio clínico una nueva 
tecnología para el estudio de la función plaquetaria, constituyéndose de paso en el «estándar de referencia» para el estudio de la función plaquetaria. En el caso de la aspirina, la agregación plaquetaria con ácido araquidónico es relativamente específica para evaluar la actividad de la COX-1 plaquetaria. Esta prueba, en ausencia de aspirina, o bien, en presencia de resistencia a la aspirina, al poner plasma rico en plaquetas en contacto con ácido araquidónico a una concentración de $500 \mu \mathrm{g} / \mathrm{mL}$, muestra la agregación plaquetaria, lo que se traduce en aumento de la transmisión de luz, cambio que es detectado por el equipo y transformado a un porcentaje de agregación final por encima de 70\% [77, 251-254] [255], como se observa en la figura 9. De otro lado, la agregación plaquetaria por debajo del $20 \%$, como se observa en la figura 10, es indicativo de antiagregación plaquetaria inducida por la vía de la COX-1, esto es, asociada con la acción de la aspirina [255]. La aspirina también disminuye la agregación plaquetaria con otros agonistas plaquetarios, entre los cuales se incluye principalmente la epinefrina $[77,252]$, el mismo que se utiliza en el PFA-100 [256], pero no se modifica con los agonistas convencionales de la agregometría plaquetaria, tales como ristocetina y colágeno, mientras que la respuestas es variable con ADP [257]. Es por ello, que el agonista de elección para el seguimiento de la respuesta a aspirina es el ácido araquidónico a una concentración de $500 \mu \mathrm{g} / \mathrm{mL}$, tomando como punto de corte $20 \%$ para definir respuesta positiva o resistencia al tratamiento.

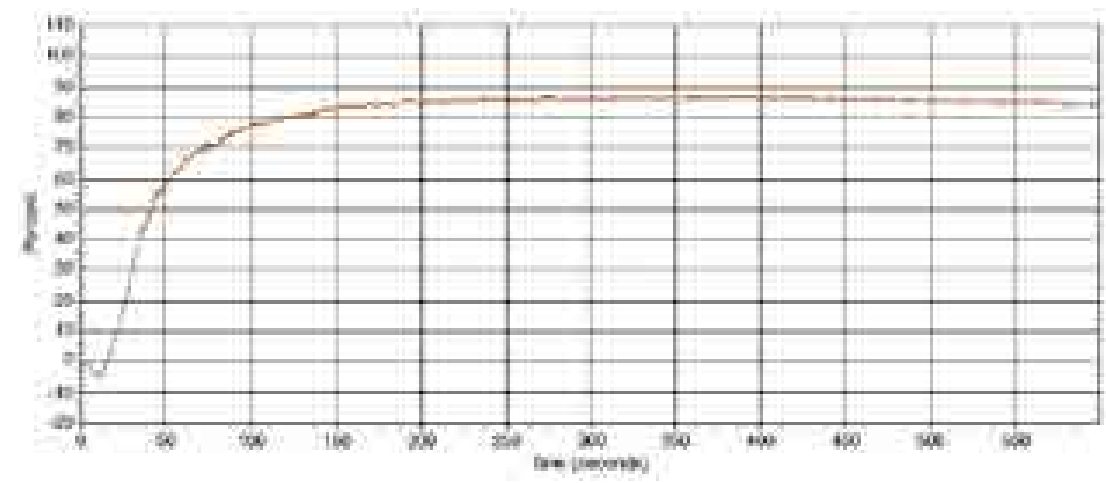

Figura 9. Agregación plaquetaria con ácido araquidónico. Paciente con resistencia a la aspirina. Cortesía Laboratorio Clínico Hematológico, Medellín, Colombia.

En el caso del monitoreo de la antiagregación con aspirina mediante agregación plaquetaria el médico debería solicitar al laboratorio clínico la prueba como «agregación plaquetaria con ácido araquidónico» o simplemente como «agregación plaquetaria para aspirina», asegurándose que el paciente tome la última dosis de aspirina antes de presentarse al laboratorio, recordando que de no hacerlo en la prueba se reflejara la actividad integra de las plaquetas no aspirinizadas que pueden dar origen a resultados inapropiados, incluida la posibilidad de resistencia a la aspirina como un falso resultado. 


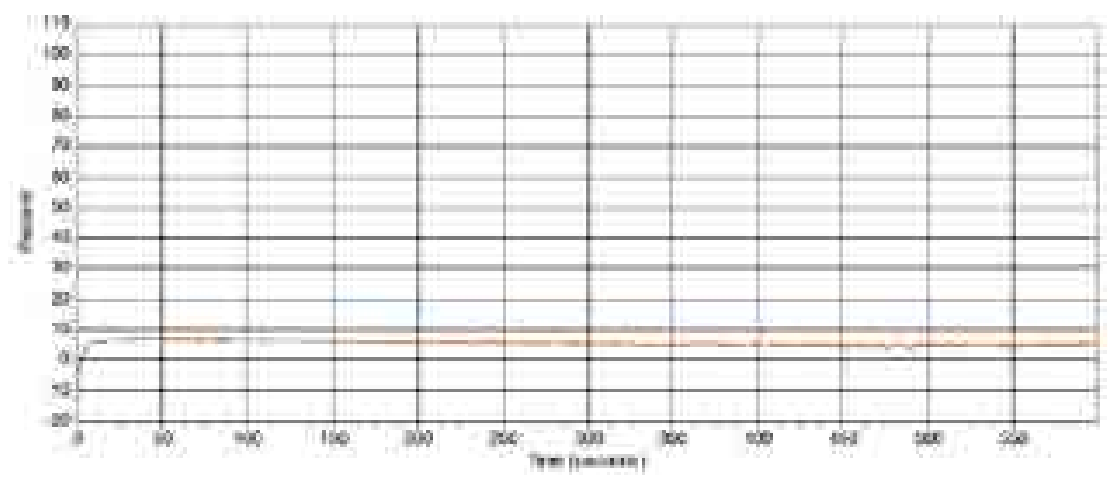

Figura 10. Agregación plaquetaria con ácido araquidónico. Paciente bajo efecto de la aspirina. Cortesía Laboratorio Clínico Hematológico, Medellín, Colombia.

\section{PFA-100}

El PFA-100 ${ }^{\circledR}$ (Siemens Healthcare Diagnostics, Inc., Deerfield, Illinois, Estados Unidos), es un sistema de evaluación de la función plaquetaria compuesto por un instrumento y una serie de cartuchos con los cuales se simula la hemostasia primaria [256, 258]. Con esta metodología, además de que sustituye el tradicional tiempo de sangría, dependiendo de los cartuchos (reactivos) que se utilicen la prueba, particularmente es útil en el tamizaje de la enfermedad de von Willebrand y en la evaluación de la antiagregación con aspirina o un inhibidor del ADP de las plaquetas, como el clopidogrel [256 ]. En el caso de la antiagregación plaquetaria por aspirina típicamente el tiempo de cierre del cartucho colágeno/ epinefrina (CEPI) se encuentra alargado (valor de referencia: 80 a 150 segundos), usualmente por encima de 180 segundos y en la mayoría de las veces por encima de 300 segundos, en tanto que el tiempo de cierre del cartucho colágeno/ADP (CADP) usualmente se encuentra dentro de los rangos normales valor de referencia: 60 a 100 segundos) [256].

Para mejor compresión de la prueba, en la figura 11 se muestran los histogramas de colágeno/epinefrina (CEPI) y colágeno/ADP (CADP) de un paciente con un PFA100 normal. Es importante resaltar que estas gráficas usualmente no llegan al médico, sino que son utilizadas como herramienta de análisis a cargo del profesional del laboratorio que hace la prueba, similar a cómo funcionan los histogramas y los dispersogramas en el caso de los hemogramas electrónicos; al médico se le informa solamente el tiempo de cierre de la prueba [259]. El resultado que recibe el médico se expresa como «tiempo de cierre» expresado en segundos para cada uno de los estudios realizados. Además del resultado numérico, el resultado de un estudio de PFA-100 puede ir acompañado de un comentario interpretativo para mejor comprensión de la prueba [260]. En la figura 12 se muestra el resultado de un PFA-100 típico de la antiagregación plaquetaria inducida por aspirina y en la figura $\mathbf{1 3}$ se muestra el resultado de un PFA-100 de un caso de resistencia a la aspirina detecta- 
do por este método [256 ]. Para mayor información sobre el PFA-100 y su utilización en la clínica se puede consultar en Medicina \& LABoratorio 2013, V19 (11-12), en el módulo La Clínica y el Laboratorio el artículo titulado «PFA-100: una nueva prueba de función plaquetaria sustituta del tiempo de sangría» [256].
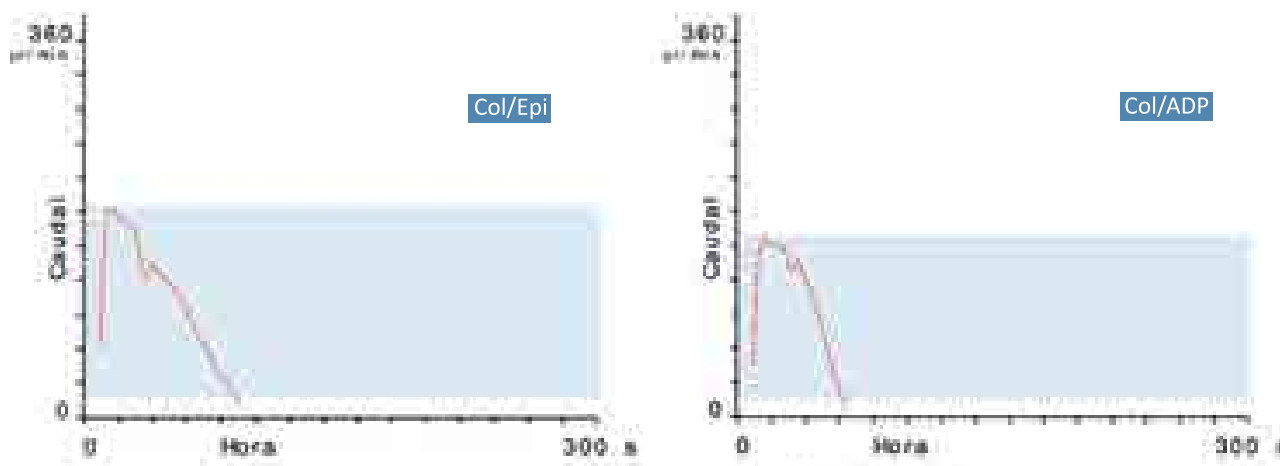

Figura 11. PFA-100. Histograma de PFA-100 normal. Mujer de 18 años a quien se le practicó una prueba de PFA-100 dentro del panel de los estudios prequirúrgicos. Tiempo de cierre colágeno/epinefrina (CEPI) 99 segundos (valor de referencia: 80 a 150 segundos); tiempo de cierre colágeno/ADP (CADP) 66 segundos (valor de referencia: 60 a 100 segundos) [256]. Cortesía del Laboratorio Clínico Hematológico, Medellín, Colombia.
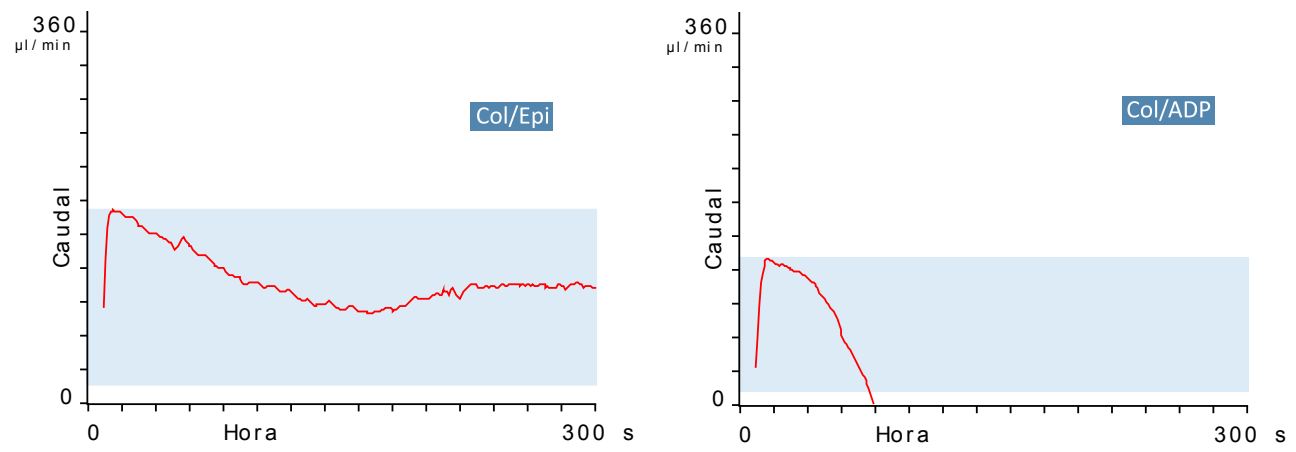

Figura 12. PFA-100. Histograma de PFA-100 (aspirina) como control de la antiagregación con aspirina. Caso en donde se logra el efecto de la droga. Hombre de 68 años a quien se le hace un PFA-100 para evidenciar la antiagregación con aspirina (100 mg/día). Tiempo de cierre colágeno/epinefrina (CEPI) > 300 segundos (valor de referencia: 80 a 150 segundos); tiempo de cierre colágeno/ADP (CADP) 80 segundos (valor de referencia: 60 a 100 segundos). El estudio muestra alargamiento del tiempo de cierre colágeno/ epinefrina con tiempo de cierre colágeno/ADP normal, compatible con antiagregación por aspirina [256]. Cortesía del Laboratorio Clínico Hematológico, Medellín, Colombia.

Desde el punto de vista de la utilidad clínica, el PFA-100 es una buena alternativa para complementar el estudio de agregación plaquetaria con ácido araquidónico, o para sustituirla cuando, por alguna razón, no está disponible en el medio [256]. No debe olvidarse que los resultados de la prueba se pueden afectar por la hemoglobina y el hematocrito (cuando están bajos) y por el recuento plaquetario (bajo) [261-264]. La prueba no se afecta cuando hay defectos de la coagulación, particularmente los relacionados con los factores, en especial con la deficiencia de 
factores VIII, IX y XI de la coagulación [265], situaciones que no deben olvidarse al momento de interpretar los resultados de la prueba.
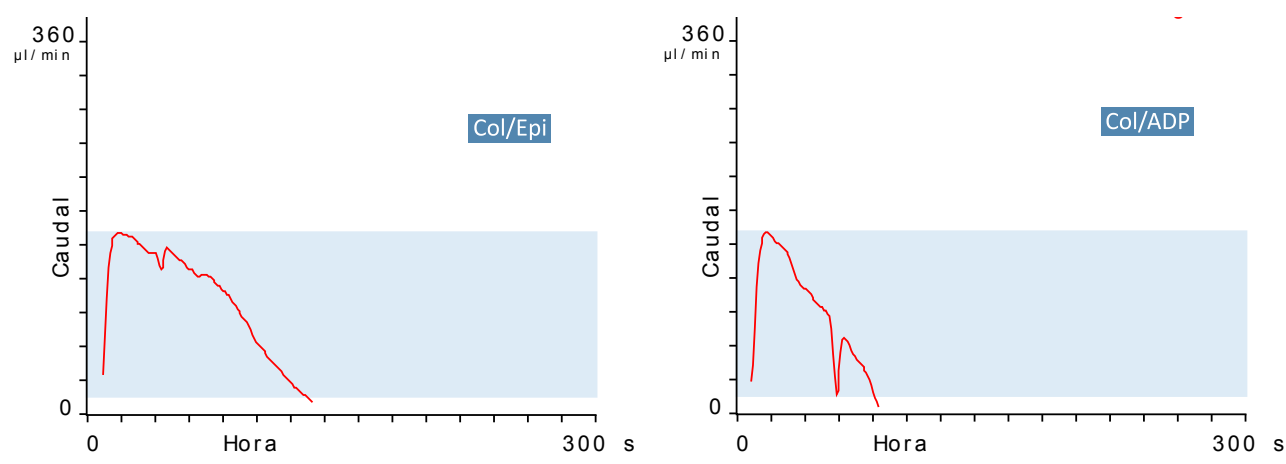

Figura 13. PFA-100. Histograma de PFA-100 (aspirina) como control de la antiagregación con aspirina. Caso en donde no se logra el efecto de la droga ("resistencia a la aspirina»). Mujer de 80 años a quien se le hace un PFA-100 para evidenciar la antiagregación con aspirina (100 mg/día). Tiempo de cierre colágeno/epinefrina (CEPI) 133 segundos (valor de referencia: 80 a 150 segundos); tiempo de cierre colágeno/ADP (CADP) 84 segundos (valor de referencia: 60 a 100 segundos). El estudio muestra tiempo de cierre colágeno/epinefrina y colágeno/ADP normales, compatible con el diagnóstico de «resistencia a la aspirina»[256]. Cortesía del Laboratorio Clínico Hematológico, Medellín, Colombia.

\section{VerifyNow ${ }^{\circledR}$}

También conocida como Ultegra RPFA (del inglés, Ultegra rapid platelet-function assay; Accumetrics, Inc., San Diego, California, Estados Unidos), es una prueba que evalúa la agregación de las plaquetas alrededor de perlas de poliestireno revestidas de fibrinógeno en respuesta al ácido araquidónico, lo que resulta en cambios en la intensidad de la señal óptica que se convierten en unidades de intervención de aspirina (ARU) [77, 253-255]. Esta prueba actualmente no está disponible en el medio; además, no ha demostrado ser más sensible que la agregometría plaquetaria con ácido araquidónico, que se considera el estándar de referencia para el monitoreo de la antiagregación plaquetaria con aspirina [78, 266-272].

\section{Correlación entre diferentes métodos para medir la actividad} antiagregante de la aspirina y detectar la resistencia a la aspirina

Como se ha expresado, en la fisiología plaquetaria intervienen múltiples vías, por lo que no existe una correlación absoluta entre las diferentes pruebas para medir la actividad antiagregante de la aspirina. La mayoría de los estudios coinciden en señalar que la prueba que mejor determina el grado de antiagregación de la aspirina es la agregometría óptica con ácido araquidónico a una concentración de $500 \mu \mathrm{g} / \mathrm{mL}$, como se ha analizado previamente, y que el PFA-100 tiene una buena correlación como se muestra en la figura 14 en donde se analizan 34 pacientes que son controlados en el Laboratorio Clínico Hematológico, Medellín Colombia, por estos dos métodos. 
En la figura 14 se muestra la correlación de la detección de la resistencia a la aspirina en nuestro medio medido por agregometría óptica con ácido araquidónico y el PFA-100. Como se observa, en el diagrama de dispersión existe una correlación negativa entre ambas pruebas, lo que indica que los valores altos (resistencia a la aspirina) con la prueba de agregación plaquetaria con ácido araquidónico se suelen corresponder en un $56 \%$ con los valores bajos (resistencia a la aspirina) del PFA-100 y viceversa (coeficiente de correlación=-0,56). Nuestros hallazgos son coherentes con los informados por Dawson y colaboradores que comparan el PFA-100 con el RPFA (del inglés, Rapid Platelet Function Analyser) [273], otro dispositivo no disponible en Colombia, para medir la función plaquetaria.

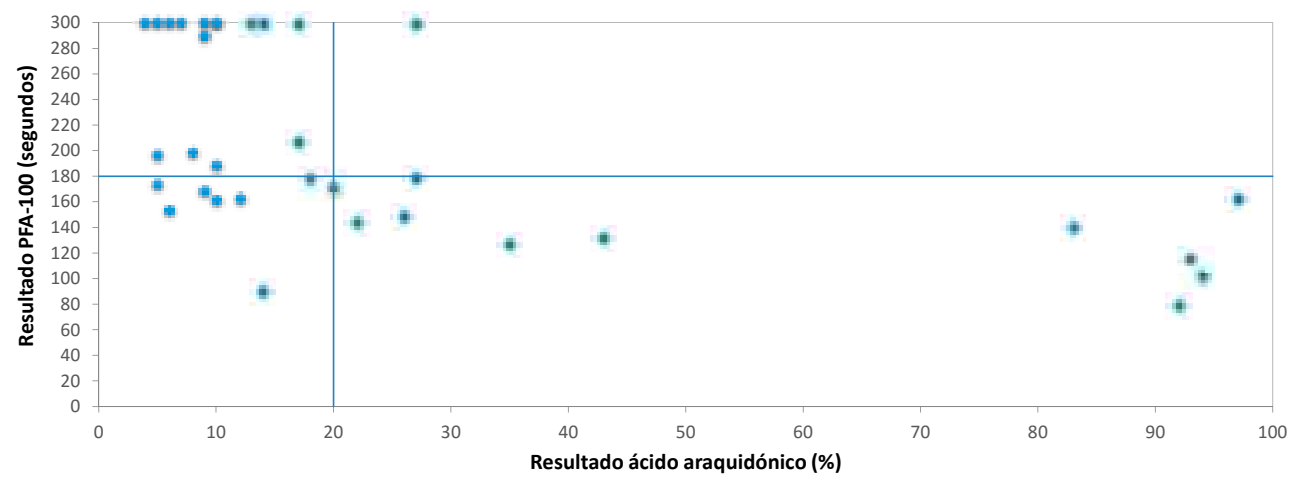

Figura 14. Diagrama de dispersión de la capacidad de la respuesta (antiagregación plaquetaria) a la aspirina medido por PFA-100 en comparación con la capacidad de respuesta a la aspirina medido por agregometría óptica con ácido araquidónico en 34 pacientes del Laboratorio Clínico Hematológico, MedeIlín, Colombia. Cada punto de datos representa un individuo. Los valores a la derecha de la línea vertical de referencia representan la resistencia a la aspirina en las pruebas por agregometría óptica con ácido araquidónico, mientras que los valores por debajo de la línea horizontal de referencia representan la resistencia a la aspirina en la prueba PFA-100.

Tomando como «estándar de referencia» la agregometría óptica con ácido araquidónico para la detección de resistencia a la aspirina en los 34 pacientes analizados en el Laboratorio Clínico Hematológico, el PFA-100 detectó correctamente la resistencia en la aspirina en el $91,7 \%(11 / 12)$ de los casos, con un solo caso $(1 / 12 ; 8,3 \%)$ detectado erróneamente como sensible (falso negativo). Entretanto, el PFA-100 detectó correctamente como sensibles a la aspirina el 68,2\% (15/22) de los casos, pero erróneamente como resistentes el 31,8\% (7/22) de ellos (falsos positivos).

Con base en lo anterior, se podría concluir que en la población seleccionada el PFA100 presenta una sensibilidad y una especificidad para detectar la resistencia a la aspirina del $91,7 \%$ y el $68,2 \%$, respectivamente, lo que demuestra una alta capacidad de esta prueba para detectar como resistente a la aspirina un paciente que es resistente, pero baja para detectar como sensible a la aspirina un paciente sensible. Por su parte, el PFA-100 presenta un valor predictivo positivo del $61,1 \%$ y un valor predictivo negativo del 93,8\%, lo cual indica que un resultado de antiagregación plaquetaria («negativo») confirma realmente que el paciente es sensible a la aspi- 
rina; no obstante, un resultado de NO antiagregación plaquetaria («positivo») no necesariamente confirma que el paciente sea resistente a la aspirina. Lo anterior sugiere que para la detección de la real resistencia a la aspirina se deben usarse varias pruebas, por ejemplo la agregometría óptica con ácido araquidónico y el PFA100, que evalúen diferentes vías de activación y agregación plaquetaria.

\section{Preanalíticos para el estudio de la función plaquetaria}

Las pruebas de función plaquetaria, como la agregometría óptica con ácido araquidónico y el PFA-100 analizados en este módulo, son muy exigentes tanto en las condiciones técnicas propiamente dichas (factores analíticos) como en las condiciones preanalíticas [263, 274, 275]. Con relación a las condiciones preanalíticas de estas pruebas, es importante tener en cuenta los siguientes aspectos $[276,277]$ :

\section{Relacionados con el laboratorio clínico a donde solicitar las pruebas}

En la medida que sea posible estas pruebas deben estar circunscritas a laboratorios clínicos especializados que dispongan de instrumentación y con experiencia de este tipo de pruebas, incluidos programas de calidad que les permita ofertar las condiciones analíticas que este tipo de medición requieren.

\section{Relacionados con la preparación del paciente}

Las condiciones del paciente para un estudio de agregación plaquetaria y para PFA-100, corresponden, en términos generales, a las que aplican a todas las pruebas de coagulación, es decir evitar dietas ricas en grasa ocho a 12 horas previas a la toma de muestra y permanecer en reposo durante 10 a 15 minutos antes de la venopunción. Se recomienda que la muestra se tome antes de las 10 A.M. debido al ciclo circadiano de la función plaquetaria [278]. Los pacientes que van a ser estudiados para medir la actividad de la aspirina deben tomar la dosis habitual antes de la toma de la muestra, debido a que en la muestra podría haber una proporción importante d plaquetas no aspirinizadas que podrían dar resultados falsamente alterados. También de abstenerse de consumir alimentos y medicamentos que pueden interferir con la prueba [256, 276, 277].

\section{Relacionados con el tipo de muestra}

La agregación plaquetaria con ácido araquidónico y el PFA-100 se realizan en sangre total anticoagulada con citrato de sodio al 3,2\%, tubo tapa azul. Para la toma de muestra, se recomienda el uso de agujas de calibre intermedio (19G a 21G), agotar por completo el vacío del tubo, tomar siempre el tubo citratado antes que tubos con cualquier aditivo o anticoagulante, y mezclar adecuadamente la muestra inmediatamente después de su obtención. De acuerdo con la prueba a realizar se requiere tomar varios tubos citratados. Durante la toma de muestra, se debe evitar punciones traumáticas o estasis venosa prolongada. 


\section{Relacionados con el manejo y conservación de las muestras}

Las muestras se deben dejar reposar en durante una hora a temperatura ambiente (entre $15^{\circ} \mathrm{C}$ y $25^{\circ} \mathrm{C}$ ), en posición vertical, y luego se centrifuga un tubo a 1000 rpm por 8 minutos para obtener plasma rico en plaquetas, y un tubo a $3.200 \mathrm{rpm}$ durante 8 minutos para obtener plasma pobre en plaquetas, el cual será empleado como blanco, en el caso de las muestras para agregación plaquetaria con ácido araquidónico [277] y no centrifugadas, en el caso del PFA-100 [276]. Las muestras no se deben refrigerar, y son solo estables durante cuatro horas siempre que se conserven a temperatura ambiente, tiempo límite para realizar los estudios. Es ideal que se evite el transporte de las muestras, incluso el transporte por tubo neumático; por ello, las muestras se deben tomar en la sede de procesamiento del examen.

\section{Cómo controlar la efectividad de la antiagregación plaquetaria y detectar la resistencia a la aspirina}

Hasta el momento no hay consenso en relación a los controles de laboratorio para evaluar la antiagregación plaquetaria y detectar la resistencia a la aspirina [77, 279]. De acuerdo con lo analizado en este módulo, similar a la manera como se controla la anticoagulación con cumarínicos [280, 281], todos los pacientes que reciben aspirina como antiagregante plaquetario, independiente de la causa por la cual se está indicando el fármaco, deberían ser monitoreados periódicamente, máxime cuando se dispone tecnología para hacerlo, como la agregación plaquetaria con ácido araquidónico y el PFA-100, disponibles en el medio y, sobre todo, si se tiene en cuenta la prevalencia tan alta de la resistencia a la aspirina. Una buena combinación, con pruebas de función plaquetaria disponibles en el medio, podría ser la agregación plaquetaria con ácido araquidónico y el PFA-100 haciendo el primer control entre dos y cuatro semanas después de haber iniciado la droga, con seguimiento de las mismas pruebas cada seis meses o cuando el paciente tenga cambios clínicos. En todos los pacientes que estando tomando aspirina, sola o asociada con otro antiagregante, que hace una manifestación tromboembólica $[282,283]$ se debe sospechar el diagnóstico de una resistencia a la aspirina [80, $90,100-116]$ y en este caso estaría indicado el estudio con estas dos pruebas para confirmar o descartar el diagnóstico de resistencia a la aspirina u otros antiagregantes como el clopidogrel [284].

\section{Manejo de la resistencia a la aspirina}

A pesar de que hay bastante información sobre la resistencia a la aspirina, aun la comunidad científica no tiene total claridad sobre cuál debe ser el manejo ideal de este problema. Ante la sospecha de resistencia a la aspirina el primer paso es descartar la falta de «adherencia» al medicamento antes de diagnosticar a un 
paciente como resistente, aun cuando las pruebas de laboratorio sean indicativas de que esto puede estar sucediendo [285-287] y en este caso, después de hacer los ajustes a la droga, repetir las pruebas antes de clasificar al paciente como resistente a la aspirina.

Si el paciente es un buen cumplidor y se descartan otros motivos de falta de respuesta, como las interacciones medicamentosas, se podrían contemplar varias acciones a seguir, como se describe a continuación.

\section{Aumentar la dosis de la aspirina}

Hay evidencia de que dosis pequeñas, de $75 \mathrm{mg}$ a $150 \mathrm{mg}$, son suficientes para alcanzar una antiagregación adecuada y disminuir los eventos cardiovasculares [288], con la ventaja de estar relacionada con menos efectos colaterales, en especial los gastrointestinales, debido a que estos son dependientes de la dosis. No obstante, algunos estudios sugieren que un aumento de la dosis podría ser suficiente [80,100,110,112,134, 195, 289-291] para resolver el problema y alcanzar un nivel de antiagregación deseado, siempre buscando la dosis mínima y demostrando su eficacia por métodos de laboratorio, como los que se han analizado en este módulo.

\section{Adicionar otros antiagregantes}

En este caso, la mayoría de los autores recomienda la adición de clopidogrel y en su defecto otro de los antiagregantes inhibidores del ADP. La adición de un inhibidor a la aspirina ha demostrado ser superior a la monoterapia en las indicaciones del síndrome coronario agudo, sin elevación del segmento ST, incluyendo pacientes sometidos a colocación de estent 87 y síndrome coronario agudo con elevación del segmento ST. Es importante anotar que así como está bien documentada la resistencia a la aspirina también puede haber resistencia al clopidogrel solo [107, 292,293 ] o asociado con la resistencia a la aspirina [294], asociado con un mayor riesgo de complicaciones aterotrombóticas como caramente se ha documentado en el medio. En estos casos se podría agregar uno de los nuevos inhibidores del ADP, como el prasugrel [295] o el ticagrelor [296, 297], solo para mencionar dos nuevas alternativas.

\section{Conclusiones}

La agregación plaquetaria con aspirina se ha convertido en el eje central de la prevención primaria y, asociada con otros antiagregantes, de la prevención secundaria de las enfermedades cardiovasculares y cerebrovasculares. En los últimos años se ha observado, asociado con múltiples mecanismos, que van desde factores demográficos hasta la taquifilaxia, pasando por factores, tan diversos, como la biodisponibilidad de la aspirina, los estados de hiperactividad plaquetaria, los poli- 
morfismo plaquetarios y las comorbilidades que pueda presentar el paciente, que un número importante de los pacientes que toman regularmente aspirina a bajas dosis desarrollan resistencia a la aspirina, que se manifiesta con complicaciones cardiovasculares, cerebrovasculares u otras formas clínicas de tromboembolismo. Afortunadamente, los laboratorios clínicos proveen pruebas, como la agregación plaquetaria con ácido araquidónico, que como el caso del control de la anticoagulación con cumarínicos, permite que todos los pacientes que reciben aspirina como antiagregante plaquetario, independiente de la causa por la cual se está indicando el fármaco, sean monitorearlos periódicamente, y más importante, se les detecte oportunamente la resistencia a la aspirina, cuando esta se presenta complicación que para algunos autores, se constituye, per se, en un nuevo factor independiente de trombosis [298].

\section{Agradecimientos}

Agradecimientos especiales a Gloria E. Escobar Gallo, Natalia M. Guevara Arismendy y Verónica J. Tangarife Castaño por el apoyo en la consecución del material gráfico, la revisión y adecuación del contenido, así como la disposición y colaboración brindada para el desarrollo y publicación de este manuscrito.

\section{Bibliografía}

1. Organization. WH, World Heart Federation, Organization. W. Global atlas of cardiovascular disease prevention and control 2011. Geneva: WHO; 2011 [consultado diciembre 20 2015]. Disponible en: http://whqlibdoc.who. int/publications/2011/9789241564373 eng. pdf2.

2. Yusuf S, Reddy S, Ounpuu S, Anand S. Global burden of cardiovascular diseases: part I: general considerations, the epidemiologic transition, risk factors, and impact of urbanization. Circulation 2001; 104:2746-2753.

3. Yusuf S, Reddy S, Ounpuu S, Anand S. Global burden of cardiovascular diseases: Part II: variations in cardiovascular disease by specific ethnic groups and geographic regions and prevention strategies. Circulation $2001 ; 104: 2855-2864$

4. García G, Ronald G, P. L-J. Uso de aspirina en la prevención de enfermedades cardiovasculares. Rev Colomb Cardiol 2008;15:223230.

5. World Health Organization. Disease and injury country estimates, Burden of Disease 2008. Geneva: WHO; 2004 [consultado en ene 2016]. Disponible en: http://www.who. int/healthinfo/global burden disease/estimates country/en/.
6. López-Jaramillo P, Casas JP, Bautista L, Serrano NC, Morillo CA. An integrated proposal to explain the epidemic of cardiovascular disease in a developing country. From socioeconomic factors to free radicals. Cardiology 2001;96:1-6.

7. Machado-Alba JE, García S, Calvo-Torres LF, Bañol-Giraldo AM. Patrones de prescripción del ácido salicílico. Rev Colomb Cardiol 2015;22:127-135.

8. Weisman SM, Graham DY. Evaluation of the benefits and risks of low-dose aspirin in the secondary prevention of cardiovascular and cerebrovascular events. Arch Intern Med 2002;162:2197-2202.

9. Srinath Reddy K, Katan MB. Diet, nutrition and the prevention of hypertension and cardiovascular diseases. Public Health Nutr 2004; 7:167-186.

10. Thompson PD, Buchner D, Pina IL, Balady GJ, Williams MA, Marcus BH, et al. Exercise and physical activity in the prevention and treatment of atherosclerotic cardiovascular disease: a statement from the Council on Clinical Cardiology (Subcommittee on Exercise, Rehabilitation, and Prevention) and the Council on Nutrition, Physical Activity, and Metabolism (Subcommittee on Physical Activity). Circulation 2003;107:3109-3116. 
11. Rigotti NA, Pasternak RC. Cigarette smoking and coronary heart disease: risks and management. Cardiol Clin 1996;14:51-68.

12. Stratton IM, Adler AI, Neil HA, Matthews DR, Manley SE, Cull CA, et al. Association of glycaemia with macrovascular and microvascular complications of type 2 diabetes (UKPDS 35): prospective observational study. BMJ 2000;321:405-412.

13. Neal B, MacMahon S, Chapman N, Blood Pressure Lowering Treatment Trialists $C$. Effects of ACE inhibitors, calcium antagonists, and other blood-pressure-lowering drugs: results of prospectively designed overviews of randomised trials. Blood Pressure Lowering Treatment Trialists' Collaboration. Lancet 2000;356:1955-1964.

14. Chobanian AV, Bakris GL, Black HR, Cushman WC, Green LA, Izzo JL, Jr., et al. Seventh report of the Joint National Committee on Prevention, Detection, Evaluation, and Treatment of High Blood Pressure. Hypertension 2003;42:1206-1252.

15. National Cholesterol Education Program Expert Panel on Detection E, Treatment of High Blood Cholesterol in A. Third Report of the National Cholesterol Education Program (NCEP) Expert Panel on Detection, Evaluation, and Treatment of High Blood Cholesterol in Adults (Adult Treatment Panel III) final report. Circulation 2002;106:3143-3421.

16. Gluckman TJ, Baranowski B, Ashen MD, Henrikson CA, McAllister M, Braunstein JB, et al. A practical and evidence-based approach to cardiovascular disease risk reduction. Arch Intern Med 2004;164:1490-1500.

17. WHO. [http://www.who.int/medicines/publications/essentialmedicines/EML2015_8-May-15. pdf]. Accessed 3 December 2015.

18. Awtry EH, Loscalzo J. Aspirin. Circulation 2000;101:1206-1218.

19. Lévesque $\mathbf{H}$, Lafont $\mathbf{O}$. L'aspirine a travers les siecles: rappel historique. Rev Med Interne 2000;21:8s-17s.

20. Ebers G. Papyros Ebers (Ebers Papyrus). Disponible en http://www.nlm.nih.gov/archive/20120918/hmd/breath/breath_exhibit/ MindBodySpirit/IIBa18.html. Consultado diciembre 2015.

21. Stone E. An account of the success of the bark of the willow in the cure of agues. Philos Trans R Soc Lond 1763; 53:195-200.

22. Buchner A. Über das Rigatellische Fiebermittel und über eine in der Weidenrinde entdeckte alcaloidische Substanz» (On Rigatelli's antipyretic [i.e., anti-fever drug] and on an alkaloid substance discovered in willow bark). Repertorium für die Pharmacie 1828;29:405-420.
23. Leroux H. Découvert de la salicine. J de Chimie Medicale 1830;6:341.

24. von Gerhardt C. Untersuchungen über die wasserfreien organischen säuren. Liebigs Annalen der Chemie und Pharmacie 1853;87:149179.

25. Kolbe $\mathbf{H}$. Über synthese der salicylsäure. Liebigs Annalen der Chemie und Pharmacie 1860;113:125-127.

26. Kolbe H, Lautemann E. Über die constitution und basicität der salicylsäure. Liebig's Annalen der Chemie 1860;115:157-206.

27. Dreser H. Pharmakologisches über aspirin (acetylsalicylsaüre). Archiv für die Gesammte Physiologie des Menschen und der Thiere (Pflügers)Pfluger's Arch 1899;76:306 -318.

28. Binz C. Vorlesungen über pharmakologie. Berlin: 1891.

29. Link KP, Overman RS, Sullivan LOR, Nuebruier CF, Scheel LD. Studies on hemorrhagic sweet clover disease. J Biol Chem $1943 ; 147: 463-473$

30. Cahn L. Acetylsalicylic acid (aspirin) as a cause of bleeding. J Oral Surg (Chic) 1945;3:336338.

31. Schaeffer JH, Blaisdell ER, Herrick SE. Hemorrhagic tendency of aspirin therapy: a case report. J Maine Med Assoc 1951;42:262-264.

32. Smith JM, Mackinnon J. Aetiology of aspirin bleeding. Lancet 1951;2:569-570.

33. Singer R. Acetylsalicylic acid, a probable cause for secondary post-tonsillectomy hemorrhage. Arch Otolaryngol 1945;42:19-20.

34. Rapp G. Cause of delayed hemorrhage after tooth extraction. J Am Dent Assoc $1947 ; 34: 484$

35. Muir A, Cossar IA. Aspirin and ulcer. Br Med J 1955;2:7-12.

36. Govan CD, Jr. The effect of salicylate administration on the prothrombin time. J Pediatr 1946;29:629-636.

37. Gibson P. Salicylic acid for coronary thrombosis? Lancet $1948 ; 1: 965$.

38. Gibson PC. Aspirin in the treatment of vascular diseases. Lancet 1949;2:1172-1174.

39. Craven LL. Acetylsalicylic acid, possible preventive of coronary thrombosis. Ann West Med Surg 1950;4:95-99.

40. Craven LL. Coronary thrombosis can be prevented. J Insur Med 1950;5:47-48.

41. Craven LL. Experiences with aspirin (acetylsalicylic acid) in the nonspecific prophylaxis of coronary thrombosis. Miss Valley Med J 1953;75:38-44. 
42. Craven LL. Prevention of coronary and cerebral thrombosis. Miss Valley Med J 1956;78:213215.

43. Times asst. editor Earl Craven dies. Los Angeles Times. 1956 Jan 9;A1.

44. Mann CC, M.L. P. The aspirin wars: Money, medicine and 100 years of rampant competition. New York, NY: Alfred A Knopf Inc; 1991:1-420. New York, NY.

45. Vane JR. Inhibition of prostaglandin synthesis as a mechanism of action for aspirin-like drugs. Nat New Biol 1971;231:232-235.

46. Fuster V, Sweeny JM. Aspirin: a historical and contemporary therapeutic overview. Circulation $2011 ; 123: 768-778$.

47. Pollack A. New York Times (New York), July 20, 2004: F1.

48. Mueller HS, Rao PS, Greenberg MA, Buttrick PM, Sussman, II, Levite HA, et al. Systemic and transcardiac platelet activity in acute myocardial infarction in man: resistance to prostacyclin. Circulation 1985;72:13361345.

49. Ackerman RH, Newman KL. Incomplete antiplatelet effect in patiens on aspirin compounds (abstract). Ann Neurol 1990;28:224.

50. Ajani UA, Ford ES, Greenland KJ, Giles WH, Mokdad AH. Aspirin use among U.S. adults: Behavioral Risk Factor Surveillance System. Am J Prev Med 2006;30:74-77.

51. Campbell CL, Smyth S, Montalescot G, Steinhubl SR. Aspirin dose for the prevention of cardiovascular disease: a systematic review. JAMA 2007;297:2018-2024.

52. Thon JN, Italiano JE. Platelets: production, morphology and ultrastructure. Handb Exp Pharmacol 2012;3-22.

53. White JG. Platelet structure. In: Platelets, edited by Michelson AD. London: Academic Press, 2013, p. 117-144.

54. Italiano JE, Hartwig JH. Megakaryocyte development and platelet formation. In: Platelets, edited by Michelson AD. London: Academic Press, 2013, p. 27-49.

55. Clemetson KJ, Clemetson JM. Platelet receptors. In: Platelets, edited by Michelson AD. London: Academic Press, 2013, p. 169-194.

56. Koseoglu S, Meyer AF, Kim D, Meyer BM, Wang Y, Dalluge JJ, et al. Analytical characterization of the role of phospholipids in platelet adhesion and secretion. Anal Chem 2015;87:413-421.

57. Offermanns $\mathbf{S}$. Activation of platelet function through $\mathrm{G}$ protein-coupled receptors. Circ Res 2006;99:1293-1304.
58. Li Z, Delaney MK, O'Brien KA, Du X. Signaling during platelet adhesion and activation. Arterioscler Thromb Vasc Biol 2010;30:23412349 .

59. Vorchheimer DA, Becker R. Platelets in atherothrombosis. Mayo Clin Proc 2006;81:5968.

60. Tselepis AD, Gerotziafas G, Andrikopoulos G, Anninos H, Vardas P. Mechanisms of platelet activation and modification of response to antiplatelet agents. Hellenic J Cardiol 2011;52:128-140.

61. Gurbel PA, Tantry US. Monitoring of antiplatelet therapy. In: Platelets, edited by Michelson AD. Amsterdam: Elseiver. Academic Press, 2013, p. 603-633.

62. Hoffman M, Monroe DM, 3rd. A cell-based model of hemostasis. Thromb Haemost 2001;85:958-965.

63. Rowland M, Riegelman S, Harris PA, ShoIkoff SD. Absorption kinetics of aspirin in man following oral administration of an aqueous solution. J Pharm Sci 1972;61:379-385.

64. Patrono C, Baigent C, Hirsh J, Roth G, American College of Chest $\mathbf{P}$. Antiplatelet drugs: American College of Chest Physicians Evidence-Based Clinical Practice Guidelines (8th Edition). Chest 2008;133:199S-233S.

65. Hutt AJ, Caldwell J, Smith RL. The metabolism of aspirin in man: a population study. Xenobiotica $1986 ; 16: 239-249$.

66. Dargan PI, Wallace CI, Jones AL. An evidence based flowchart to guide the management of acute salicylate (aspirin) overdose. Emerg Med J 2002;19:206-209.

67. Roth GJ, Stanford N, Jacobs JW, Majerus PW. Acetylation of prostaglandin synthetase by aspirin. Purification and properties of the acetylated protein from sheep vesicular gland. Biochemistry 1977; 16:4244-4248.

68. Roth GJ, Majerus PW. The mechanism of the effect of aspirin on human platelets. I. Acetylation of a particulate fraction protein. J Clin Invest $1975 ; 56: 624-632$.

69. Roth GJ, Stanford N, Majerus PW. Acetylation of prostaglandin synthase by aspirin. Proc Natl Acad Sci U S A 1975;72:3073-3076.

70. Burch JW, Stanford N, Majerus PW. Inhibition of platelet prostaglandin synthetase by oral aspirin. J Clin Invest 1978;61:314-319.

71. Roth GJ, Calverley DC. Aspirin, platelets, and thrombosis: theory and practice. Blood 1994;83:885-898.

72. Patrono C, Bachmann F, Baigent C, Bode C, De Caterina R, Charbonnier B, et al. Expert consensus document on the use of antiplatelet agents. The task force on the use of antiplate- 
let agents in patients with atherosclerotic cardiovascular disease of the European society of cardiology. Eur Heart J 2004;25:166-181.

73. van Pampus EC, Huijgens PC, Zevenbergen A, Twaalfhoven $H$, van Kamp GJ, Langenhuijsen MM. Influence of aspirin on human megakaryocyte prostaglandin synthesis. Eur J Haematol 1993;50:264-268.

74. Roth GJ, Siok CJ. Acetylation of the $\mathrm{NH}_{2}-$ terminal serine of prostaglandin synthetase by aspirin. J Biol Chem 1978;253:3782-3784.

75. Patrono C, Ciabattoni G, Patrignani P, Pugliese F, Filabozzi P, Catella F, et al. Clinical pharmacology of platelet cyclooxygenase inhibition. Circulation 1985;72:1177-1184.

76. Patrono C. Aspirin resistance: definition, mechanisms and clinical read-outs. J Thromb Haemost $2003 ; 1: 1710-1713$.

77. Michelson AD, Cattaneo M, Eikelboom JW, Gurbel P, Kottke-Marchant $K$, Kunicki TJ, et al. Aspirin resistance: position paper of the Working Group on Aspirin Resistance. J Thromb Haemost 2005;3:1309-1311.

78. Hankey GJ, Eikelboom JW. Aspirin resistance. Lancet 2006;367:606-617.

79. Vejar M, Hackett D, Brunelli C, Spallarossa P, Ianetti M, Galassi AR, et al. Comparison of low-dose aspirin and coronary vasodilators in acute unstable angina. Circulation 1990;81:14-11; discussion I22-13.

80. Helgason CM, Bolin KM, Hoff JA, Winkler SR, Mangat A, Tortorice KL, et al. Development of aspirin resistance in persons with previous ischemic stroke. Stroke 1994;25:23312336.

81. Weber AA, Przytulski B, Schanz A, Hohlfeld T, Schror K. Towards a definition of aspirin resistance: a typological approach. Platelets 2002;13:37-40.

82. De Gaetano G, Cerletti C. Aspirin resistance: a revival of platelet aggregation tests? J Thromb Haemost 2003;1:2048-2050.

83. Mason PJ, Freedman JE, Jacobs AK. Aspirin resistance: current concepts. Rev Cardiovasc Med 2004;5:156-163.

84. Martin CP, Talbert RL. Aspirin resistance: an evaluation of current evidence and measurement methods. Pharmacotherapy 2005;25:942-953.

85. Dhatariya KK. Aspirin for everyone over 50 ? Don't forget aspirin resistance. BMJ 2005;331:161; author reply 161 .

86. Wang TH, Bhatt DL, Topol EJ. Aspirin resistance: an emerging clinical entity. Eur Heart J 2005; 93:2-8.

87. Steinhubl SR, Charnigo R, Moliterno DJ.
Resistance to antiplatelet resistance is it justified? J Am Coll Cardiol 2005;45:1757-1758.

88. Michos ED, Ardehali R, Blumenthal RS, Lange RA, Ardehali H. Aspirin and clopidogrel resistance. Mayo Clin Proc 2006;81:518526.

89. Pamukcu B. A review of aspirin resistance; definition, possible mechanisms, detection with platelet function tests, and its clinical outcomes. J Thromb Thrombolysis 2007;23:213222.

90. Hovens MM, Snoep JD, Eikenboom JC, van der Bom JG, Mertens BJ, Huisman MV. Prevalence of persistent platelet reactivity despite use of aspirin: a systematic review. Am Heart J 2007;153:175-181.

91. Divani AA, Zantek ND, Borhani-Haghighi A, Rao GH. Antiplatelet therapy: aspirin resistance and all that jazz! Clin Appl Thromb Hemost 2013;19:5-18.

92. Li J, Song $M$, Jian $Z$, Guo $\mathbf{W}$, Chen G, Jiang $\mathbf{G}$, et al. Laboratory aspirin resistance and the risk of major adverse cardiovascular events in patients with coronary heart disease on confirmed aspirin adherence. J Atheroscler Thromb 2014;21:239-247.

93. Valis M, Krajickova D, Maly J, Maly R, Fatorova I, Vysata O, et al. Aspirin Resistance in Neurovascular Diseases. Acta Medica (Hradec Kralove) 2014;57:157-161.

94. Cai G, Zhou W, Lu Y, Chen P, Lu Z, Fu Y. Aspirin resistance and other aspirin-related concerns. Neurol Sci 2015.

95. Sudoyo AW. Aspirin resistance and its importance. Acta Med Indones 2015;47:87.

96. Naimo PS, McGiffin D, Konstantinov IE. Aspirin resistance in the era of personalized medicine: Should we not take it personally? J Thorac Cardiovasc Surg 2015;150:e99-e100.

97. Cai G, Zhou W, Lu Y, Chen P, Lu Z, Fu Y. Aspirin resistance and other aspirin-related concerns. Neurol Sci 2016;37:181-189.

98. Tantry US, Bliden KP, Gurbel PA. Overestimation of platelet aspirin resistance detection by thrombelastograph platelet mapping and validation by conventional aggregometry using arachidonic acid stimulation. J Am Coll Cardiol 2005;46:1705-1709.

99. Sane DC, McKee SA, Malinin AI, Serebruany VL. Frequency of aspirin resistance in patients with congestive heart failure treated with antecedent aspirin. Am J Cardiol 2002;90:893895.

100.Grotemeyer KH. Effects of acetylsalicylic acid in stroke patients. Evidence of nonresponders in a subpopulation of treated patients. Thromb Res 1991;63:587-593. 
101.Grotemeyer KH, Scharafinski HW, Husstedt IW. Two-year follow-up of aspirin responder and aspirin non responder. A pilot-study including 180 post-stroke patients. Thromb Res 1993;71:397-403.

102.Christiaens L, Macchi L, Herpin D, Coisne D, Duplantier C, Allal J, et al. Resistance to aspirin in vitro at rest and during exercise in patients with angiographically proven coronary artery disease. Thromb Res 2002;108:115119.

103.Macchi L, Christiaens L, Brabant S, Sorel N, Allal J, Mauco G, et al. Resistance to aspirin in vitro is associated with increased platelet sensitivity to adenosine diphosphate. Thromb Res 2002;107:45-49.

104.Andersen $K$, Hurlen $M$, Arnesen $H$, Seljeflot $\mathbf{I}$. Aspirin non-responsiveness as measured by PFA-100 in patients with coronary artery disease. Thromb Res 2002;108:37-42.

105.Grundmann $K$, Jaschonek $K$, Kleine B, Dichgans J, Topka H. Aspirin non-responder status in patients with recurrent cerebral ischemic attacks. J Neurol 2003;250:63-66.

106.Wang JC, Aucoin-Barry D, Manuelian D, Monbouquette R, Reisman M, Gray W, et al. Incidence of aspirin nonresponsiveness using the Ultegra Rapid Platelet Function Assay-ASA. Am J Cardiol 2003;92:1492-1494.

107.Gurbel PA, Bliden KP, Hiatt BL, O'Connor CM. Clopidogrel for coronary stenting: response variability, drug resistance, and the effect of pretreatment platelet reactivity. Circulation 2003; 107:2908-2913.

108.Friend M, Vucenik I, Miller M. Research pointers: Platelet responsiveness to aspirin in patients with hyperlipidaemia. BMJ 2003;326:8283.

109.Macchi L, Christiaens L, Brabant S, Sorel N, Ragot S, Allal J, et al. Resistance in vitro to low-dose aspirin is associated with platelet PIA1 (GP IIIa) polymorphism but not with C807T(GP Ia/IIa) and C-5T Kozak (GP Ibalpha) polymorphisms. J Am Coll Cardiol 2003;42:1115-1119.

110.Alberts MJ, Bergman DL, Molner E, Jovanovic BD, Ushiwata I, Teruya J. Antiplatelet effect of aspirin in patients with cerebrovascular disease. Stroke 2004;35:175-178.

111.Zhang $Y$, Liang J, Zhou YJ, Yuan H, Zhang $\mathbf{Y Z}$, Dong L. [Study on the relationship between aspirin resistance and incidence of myonecrosis after non-emergent percutaneous coronary intervention]. Zhonghua Xin Xue Guan Bing Za Zhi 2005;33:695-699.

112. Lee PY, Chen WH, Ng W, Cheng $X$, Kwok JY, Tse HF, et al. Low-dose aspirin increases aspirin resistance in patients with coronary artery disease. Am J Med 2005;118:723-727.
113.Borna C, Lazarowski E, van Heusden C, Ohlin $\mathbf{H}$, Erlinge D. Resistance to aspirin is increased by ST-elevation myocardial infarction and correlates with adenosine diphosphate levels. Thromb J 2005;3:10.

114.Hobikoglu GF, Norgaz T, Aksu H, Ozer O, Erturk M, Nurkalem Z, et al. High frequency of aspirin resistance in patients with acute coronary syndrome. Tohoku J Exp Med 2005;207:59-64.

115.Poston RS, Gu J, Brown JM, Gammie JS, White C, Nie L, et al. Endothelial injury and acquired aspirin resistance as promoters of regional thrombin formation and early vein graft failure after coronary artery bypass grafting. ] Thorac Cardiovasc Surg 2006;131:122-130.

116. Crescente M, Di Castelnuovo A, Iacoviello L, Vermylen J, Cerletti C, de Gaetano G. Response variability to aspirin as assessed by the platelet function analyzer (PFA)-100. A systematic review. Thromb Haemost 2008;99:1426.

117.Shen H, Herzog $W$, Drolet $M$, Pakyz R, Newcomer S, Sack $\mathbf{P}$, et al. Aspirin Resistance in healthy drug-naive men versus women (from the Heredity and Phenotype Intervention Heart Study). Am J Cardiol 2009;104:606-612.

118.Aydinalp A, Atar I, Gulmez O, Atar A, Acikel S, Bozbas $\mathbf{H}$, et al. The clinical significance of aspirin resistance in patients with chest pain. Clin Cardiol 2010;33:E1-7.

119.Ozben S, Ozben B, Tanrikulu AM, Ozer $\mathbf{F}$, Ozben $\mathbf{T}$. Aspirin resistance in patients with acute ischemic stroke. J Neurol 2011;258:1979-1986.

120.Phankingthongkum $R$, Panchavinnin $P$, Chinthammitr $Y$, Tresukosol D, Chotinaiwattarakul $C$, Tungsubutra $W$, et al. Aspirin resistance in Thai patients with chronic stable angina. J Med Assoc Thai 2013;96 Suppl 2:S146-151.

121.Yi X, Zhou Q, Lin J, Chi L. Aspirin resistance in Chinese stroke patients increased the rate of recurrent stroke and other vascular events. Int J Stroke 2013;8:535-539.

122. Chadha DS, Sumana B, Karthikeyan G, Jayaprasad V, Arun SS. Prevalence of aspirin resistance in Asian-Indian patients with stable coronary artery disease. Catheter Cardiovasc Interv 2014.

123.Grimaldi R, Bisi $M$, Lonni E, Beggiato $E$, Valpreda A, Lococo MF, et al. Laboratory aspirin resistance reversibility in diabetic patients: a pilot study using different pharmaceutical formulations. Cardiovasc Drugs Ther 2014;28:323-329.

124.Aksu HU, Oner E, Celik O, Isiksacan N, Aksu $\mathbf{H}$, Uzun S, et al. Aspirin resistance in patients undergoing hemodialysis and effect of 
hemodialysis on aspirin resistance. Clin Appl Thromb Hemost 2015;21:82-86.

125. Habizal NH, Abdul Halim S, Bhaskar $S$, Wan Bebakar WM, Abdullah JM. Prevalence of aspirin resistance in diabetic patients and its associated factors. Malays $\mathrm{J}$ Med Sci 2015;22:50-57.

126. Lewszuk AJ, Postula M, Madycki G, Staszkiewicz W, Opolski G, Eberhardt A. Evaluation of aspirin resistance and the presence of unstable carotid plaque in patients undergoing carotid endarterectomy. Kardiol Pol 2015;73:255-260.

127.Derle E, Ocal R, Kibaroglu S, Celikkol C, Bayraktar N, Verdi H, et al. Aspirin resistance in cerebrovascular disease and the role of glycoprotein IIIa polymorphism in Turkish stroke patients. Blood Coagul Fibrinolysis 2016;27:169-175.

128. Hayden M, Pignone M, Phillips C, Mulrow C. Aspirin for the primary prevention of cardiovascular events: a summary of the evidence for the U.S. Preventive Services Task Force. Ann Intern Med 2002;136:161-172.

129.Raju N, Sobieraj-Teague M, Hirsh J, O'Donnell M, Eikelboom J. Effect of aspirin on mortality in the primary prevention of cardiovascular disease. Am J Med 2011;124:621629.

130.Bousser MG, Eschwege E, Haguenau M, Lefaucconnier JM, Thibult $N$, Touboul $D$, et al. «AICLA» controlled trial of aspirin and dipyridamole in the secondary prevention of athero-thrombotic cerebral ischemia. Stroke $1983 ; 14: 5-14$

131.Lewis HD, Jr., Davis JW, Archibald DG, Steinke WE, Smitherman TC, Doherty JE, 3rd, et al. Protective effects of aspirin against acute myocardial infarction and death in men with unstable angina. Results of a Veterans Administration Cooperative Study. N Engl J Med 1983;309:396-403.

132.Farrell B, Godwin J, Richards S, Warlow C. The United Kingdom transient ischaemic attack (UK-TIA) aspirin trial: final results. J Neurol Neurosurg Psychiatry 1991;54:1044-1054.

133.Juul-Moller $S$, Edvardsson N, Jahnmatz B, Rosen A, Sorensen S, Omblus R. Double-blind trial of aspirin in primary prevention of myocardial infarction in patients with stable chronic angina pectoris. The Swedish Angina Pectoris Aspirin Trial (SAPAT) Group. Lancet 1992;340:1421-1425.

134.Patrono C, Coller B, FitzGerald GA, Hirsh J, Roth G. Platelet-active drugs: the relationships among dose, effectiveness, and side effects: the Seventh ACCP Conference on Antithrombotic and Thrombolytic Therapy. Chest 2004; $126: 234$ S-264S.
135.Eikelboom JW, Hirsh J, Weitz JI, Johnston M, Yi Q, Yusuf S. Aspirin-resistant thromboxane biosynthesis and the risk of myocardial infarction, stroke, or cardiovascular death in patients at high risk for cardiovascular events. Circulation 2002;105:1650-1655.

136.Gum PA, Kottke-Marchant $K$, Welsh PA, White J, Topol EJ. A prospective, blinded determination of the natural history of aspirin resistance among stable patients with cardiovascular disease. J Am Coll Cardiol 2003;41:961-965.

137.Sacco RL, Kasner SE, Broderick JP, Caplan LR, Connors JJ, Culebras A, et al. An updated definition of stroke for the 21st century: a statement for healthcare professionals from the American Heart Association/American Stroke Association. Stroke 2013;44:20642089.

138.Koton $S$, Tsabari $R$, Molshazki N, Kushnir M, Shaien R, Eilam A, et al. Burden and outcome of prevalent ischemic brain disease in a national acute stroke registry. Stroke 2013;44:3293-3297.

139.Likosky DJ, Lee K, Brown DM, Amin A, Dressler DD, Krakow D. Evidence-based medicine: Review of guidelines and trials in the prevention of secondary stroke J Hosp Med 2008; 3:S3-S19.

140.Vaartjes I, van Dis I, Grobbee DE, Bots ML. The dynamics of mortality in follow-up time after an acute myocardial infarction, lower extremity arterial disease and ischemic stroke. BMC Cardiovasc Disord 2010;10:57.

141.Spence JD. Secondary stroke prevention. Nat Rev Neurol 2010;6:477-486.

142. Kernan WN, Ovbiagele B, Black HR, Bravata DM, Chimowitz MI, Ezekowitz MD, et al. Guidelines for the prevention of stroke in patients with stroke and transient ischemic attack: a guideline for healthcare professionals from the American Heart Association/American Stroke Association. Stroke 2014;45:21602236.

143.Klein-Ritter D. An evidence-based review of the AMA/AHA guideline for the primary prevention of ischemic stroke. Geriatrics 2009;64:16$20,28$.

144. Furie KL, Kasner SE, Adams RJ, Albers GW, Bush RL, Fagan SC, et al. Guidelines for the prevention of stroke in patients with stroke or transient ischemic attack: a guideline for healthcare professionals from the american heart association/american stroke association. Stroke 2011;42:227-276.

145.Hsu LC, Fuh JL. Aspirin resistance and ischemic stroke outcome: fact or fiction? J Chin Med Assoc 2012;75:549-550.

146.Zheng AS, Churilov L, Colley RE, Goh C, 
Davis SM, Yan B. Association of aspirin resistance with increased stroke severity and infarct size. JAMA Neurol 2013;70:208-213.

147.Kim JT, Heo SH, Lee JS, Choi MJ, Choi KH, Nam TS, et al. Aspirin resistance in the acute stages of acute ischemic stroke is associated with the development of new ischemic lesions. PLoS One 2015;10:e0120743.

148.Agayeva N, Topcuoglu MA, Arsava EM. The Interplay between Stroke Severity, Antiplatelet Use, and Aspirin Resistance in Ischemic Stroke. J Stroke Cerebrovasc Dis 2016;25:397-403.

149.Oh MS, Yu KH, Lee JH, Jung S, Kim C, Jang MU, et al. Aspirin resistance is associated with increased stroke severity and infarct volume. Neurology 2016.

150.Goodlin RC, Haesslein HO, Fleming J. Aspirin for the treatment of recurrent toxaemia. Lancet $1978 ; 2: 51$.

151.Sibai B, Dekker G, Kupferminc M. Preeclampsia. Lancet 2005;365:785-799.

152.Duley L, Henderson-Smart D, Knight $M$, King J. Antiplatelet drugs for prevention of pre-eclampsia and its consequences: systematic review. BMJ 2001;322:329-333.

153. Bussolino F, Benedetto C, Massobrio M, Camussi G. Maternal vascular prostacyclin activity in pre-eclampsia. Lancet 1980;2:702.

154.Wojtowicz A, Undas A, Huras H, Musial J, Rytlewski K, Reron A, et al. Aspirin resistance may be associated with adverse pregnancy outcomes. Neuro Endocrinol Lett 2011;32:334339.

155.Voelker R. USPSTF: Low-dose aspirin may help reduce risk of preeclampsia. JAMA 2014;311:2055.

156. LeFevre ML, Force USPST. Low-dose aspirin use for the prevention of morbidity and mortality from preeclampsia: U.S. Preventive Services Task Force recommendation statement. Ann Intern Med 2014;161:819-826.

157.Bond S. US Preventive Services Task Force guideline supports low-dose aspirin for prevention of preeclampsia. J Midwifery Womens Health 2015;60:222-223.

158. Moore GS, Allshouse AA, Post AL, Galan HL, Heyborne KD. Early initiation of lowdose aspirin for reduction in preeclampsia risk in high-risk women: a secondary analysis of the MFMU High-Risk Aspirin Study. J Perinatol 2015;35:328-331.

159. Moore GS, Allshouse AA, Winn VD, Galan HL, Heyborne KD. Baseline placental growth factor levels for the prediction of benefit from early aspirin prophylaxis for preeclampsia prevention. Pregnancy Hypertens 2015;5:280286.
160.Xu TT, Zhou F, Deng CY, Huang GQ, Li JK, Wang XD. Low-dose aspirin for preventing preeclampsia and its complications: A meta-analysis. J Clin Hypertens (Greenwich) 2015;17:567-573.

161.Gan J, He H, Qi H. Preventing preeclampsia and its fetal complications with low-dose aspirin in East Asians and non-East Asians:A systematic review and meta-analysis. Hypertens Pregnancy 2016;1-10.

162.0'Gorman N, Wright D, Rolnik DL, Nicolaides KH, Poon LC. Study protocol for the randomised controlled trial: combined multimarker screening and randomised patient treatment with ASpirin for evidence-based PREeclampsia prevention (ASPRE). BMJ Open 2016;6:e011801.

163.Roberge S, Odibo AO, Bujold E. Aspirin for the Prevention of Preeclampsia and Intrauterine Growth Restriction. Clin Lab Med 2016;36:319-329.

164.Askie LM, Duley L, Henderson-Smart DJ, Stewart LA, Group PC. Antiplatelet agents for prevention of pre-eclampsia: a meta-analysis of individual patient data. Lancet 2007;369:1791-1798.

165. Navaratnam $K$, Alfirevic A, Alfirevic Z. Low dose aspirin and pregnancy: how important is aspirin resistance? BJOG 2016.

166. Nicolaides A, Hull RD, Fareed J, Cardiovascular Disease E, Research T, European Venous F, et al. Thrombophilia. Clin Appl Thromb Hemost 2013;19:177-187.

167.Lim MY, Moll S. Thrombophilia. Vasc Med 2015;20:193-196.

168.Alonso A, Soto I, Urgelles MF, Corte JR, Rodriguez MJ, Pinto CR. Acquired and inherited thrombophilia in women with unexplained fetal losses. Am J Obstet Gynecol 2002;187:13371342.

169.Jamal A, Hantoshzadeh S, Hekmat H, Abbasi S. The association of thrombophilia with fetal growth restriction. Arch Iran Med 2010;13:482-485.

170.Kovac M, Mitic G, Mikovic Z, Djordjevic V, Savic O, Mandic V, et al. Thrombophilia in women with pregnancy-associated complications: fetal loss and pregnancy-related venous thromboembolism. Gynecol Obstet Invest 2010;69:233-238.

171.Tranquilli AL, Saccucci $F$, Giannubilo $S R$, Cecati M, Nocchi L, Lorenzi S, et al. Unexplained fetal loss: the fetal side of thrombophilia. Fertil Steril 2010;94:378-380.

172. McNamee K, Dawood F, Farquharson RG. Thrombophilia and early pregnancy loss. Best Pract Res Clin Obstet Gynaecol 2012;26:91102. 
173.Velásquez AI, Carmona V, Ramos G. El síndrome de la plaqueta pegajosa. Serie de casos en gestantes en el Hospital Militar Central y revisión de literatura. Rev Colomb Obstret Ginecol 2004;55:232-239.

174. Campuzano-Maya G, Escobar-Gallo GE. Síndrome de plaqueta pegajosa. Medicina \& Laboratorio 2014;20:513-528.

175.Parra-Ortega I, Ruíz-Argüelles GJ. Trombofilia multifactorial en México: descripción del caso en 18 pacientes mestizos mexicanos con el síndrome de las plaquetas pegajosas Med Int Mex 2006;22:93-96.

176.Parra-Ortega I, Estrada-Gómez R, J. R-AG. Síndrome de las plaquetas pegajosas, la condición de trombofilia heredada más frecuente en pacientes mexicanos. Medicina Universitaria 2007; 9 20-23.

177.Rodríguez-Pérez LM, Castillo-González D, Tejada-González M, Zamora-González Y, Cabrera-Payne Y, Fonseca-Polanco C. Frecuencia del síndrome de plaquetas pegajosas en pacientes con pérdidas fetales recurrentes. Rev Cub Hematol Inmunol y Hemoter 2014;30:374-380.

178.Chen WH, Lee PY, Ng W, Kwok JY, Cheng $\mathbf{X}$, Lee SW, et al. Relation of aspirin resistance to coronary flow reserve in patients undergoing elective percutaneous coronary intervention. Am J Cardiol 2005;96:760-763.

179.Christiaens L, Ragot S, Mergy J, Allal J, Macchi L. Major clinical vascular events and aspirin-resistance status as determined by the PFA-100 method among patients with stable coronary artery disease: a prospective study. Blood Coagul Fibrinolysis 2008;19:235-239.

180.Gum PA, Kottke-Marchant $K$, Poggio ED, Gurm H, Welsh PA, Brooks L, et al. Profile and prevalence of aspirin resistance in patients with cardiovascular disease. Am J Cardiol 2001;88:230-235.

181. McKee SA, Sane DC, Deliargyris EN. Aspirin resistance in cardiovascular disease: a review of prevalence, mechanisms, and clinical significance. Thromb Haemost 2002;88:711-715.

182. Eikelboom JW, Hankey GJ. Aspirin resistance: a new independent predictor of vascular events? J Am Coll Cardiol 2003;41:966-968.

183. Hankey GJ, Eikelboom JW. Aspirin resistance. BMJ 2004;328:477-479.

184. Needs CJ, Brooks PM. Clinical pharmacokinetics of the salicylates. Clin Pharmacokinet 1985;10:164-177.

185. Catella-Lawson F, Reilly MP, Kapoor SC, Cucchiara AJ, DeMarco S, Tournier B, et al. Cyclooxygenase inhibitors and the antiplatelet effects of aspirin. N Engl J Med 2001;345:18091817.
186. FitzGerald GA. Parsing an enigma: the pharmacodynamics of aspirin resistance. Lancet 2003;361:542-544.

187. Cheema AA. Should people on aspirin avoid Ibuprofen? A review of the literature. Cardiol Rev 2004;12:174-176.

188. MacDonald TM, Wei L. Effect of ibuprofen on cardioprotective effect of aspirin. Lancet 2003;361:573-574.

189.Capone ML, Sciulli MG, Tacconelli S, Grana M, Ricciotti E, Renda G, et al. Pharmacodynamic interaction of naproxen with low-dose aspirin in healthy subjects. J Am Coll Cardiol 2005;45:1295-1301.

190.Williams FM. Clinical significance of esterases in man. Clin Pharmacokinet 1985;10:392-403.

191.Anand BS, Sanduja SK, Lichtenberger LM. Effect of omeprazole on the bioavailability of aspirin: a randomized controlled study on healthy volunteers. Gastroenterology 1999;116:A371.

192.Iñarrea $P$, Esteva $F$, Cornudella $R$, Lanas A. Omeprazole does not interfere with the antiplatelet effect of low-dose aspirin in man. Scand J Gastroenterol 2000;35:242-246.

193.González-Conejero R, Rivera J, Corral J, Acuña C, Guerrero JA, Vicente V. Biological assessment of aspirin efficacy on healthy individuals: heterogeneous response or aspirin failure? Stroke 2005;36:276-280.

194.Coma-Canella I, Velasco A, Castano S. Prevalence of aspirin resistance measured by PFA-100. Int J Cardiol 2005;101:71-76.

195.Stejskal D, Vaclavik J, Lacnak B, Proskova J. Aspirin resistance measured by cationic propyl gallate platelet aggregometry and recurrent cardiovascular events during 4 years of follow-up. Eur J Intern Med 2006;17:349-354.

196. Modica A, Karlsson F, Mooe T. Platelet aggregation and aspirin non-responsiveness increase when an acute coronary syndrome is complicated by an infection. J Thromb Haemost 2007;5:507-511.

197.Kahraman G, Sahin T, Kilic T, Baytugan NZ, Agacdiken A, Ural E, et al. The frequency of aspirin resistance and its risk factors in patients with metabolic syndrome. Int J Cardiol 2007;115:391-396.

198.Cagirci G, Ozdemir O, Geyik B, Cay S, Ozturk S, Aras D, et al. The prevalence of aspirin resistance in patients with metabolic syndrome. Turk Kardiyol Dern Ars 2009;37:461-466.

199.American Diabetes A. 8. Cardiovascular Disease and Risk Management. Diabetes Care 2016;39 Suppl 1:S60-71.

200.Larsson PT, Wallen NH, Hjemdahl P. Norepinephrine-induced human platelet activation in vivo is only partly counteracted by aspirin. 
Circulation 1994;89:1951-1957.

201.Pamukcu B, Oflaz H, Acar RD, Umman S, Koylan N, Umman B, et al. The role of exercise on platelet aggregation in patients with stable coronary artery disease: exercise induces aspirin resistant platelet activation. J Thromb Thrombolysis 2005;20:17-22.

202.Valles J, Santos MT, Aznar J, Osa A, Lago A, Cosin J, et al. Erythrocyte promotion of platelet reactivity decreases the effectiveness of aspirin as an antithrombotic therapeutic modality: the effect of low-dose aspirin is less than optimal in patients with vascular disease due to prothrombotic effects of erythrocytes on platelet reactivity. Circulation 1998;97:350355.

203.Karim S, Habib A, Levy-Toledano S, Maclouf J. Cyclooxygenase- 1 and -2 of endothelial cells utilize exogenous or endogenous arachidonic acid for transcellular production of thromboxane. J Biol Chem 1996;271:1204212048.

204.Pawlowski NA, Kaplan G, Hamill AL, Cohn ZA, Scott WA. Arachidonic acid metabolism by human monocytes. Studies with plateletdepleted cultures. J Exp Med 1983;158:393412.

205.Konieczkowski M, Skrinska VA. Increased synthesis of thromboxane $A(2)$ and expression of procoagulant activity by monocytes in response to arachidonic acid in diabetes mellitus. Prostaglandins Leukot Essent Fatty Acids 2001;65:133-138.

206.Rocca B, Secchiero P, Ciabattoni G, Ranelletti FO, Catani L, Guidotti L, et al. Cyclooxygenase-2 expression is induced during human megakaryopoiesis and characterizes newly formed platelets. Proc Natl Acad Sci U S A 2002;99:7634-7639.

207.Cheng Y, Austin SC, Rocca B, Koller BH, Coffman TM, Grosser T, et al. Role of prostacyclin in the cardiovascular response to thromboxane $A_{2}$. Science 2002;296:539-541.

208.De Gaetano G, Carriero MR, Cerletti C, Mussoni L. Low dose aspirin does not prevent fibrinolytic response to venous occlusion. Biochem Pharmacol 1986;35:3147-3150.

209.Rao GH, Escolar G, White JG. Epinephrine reverses the inhibitory influence of aspirin on platelet-vessel wall interactions. Thromb Res 1986;44:65-74.

210. Mustonen $\mathbf{P}$, van Willigen G, Lassila R. Epinephrine--via activation of p38-MAPK--abolishes the effect of aspirin on platelet deposition to collagen. Thromb Res 2001;104:439-449.

211.Demiroglu H. Elevated erythrocyte aggregation as a predisposing factor to aspirin resistance. Thromb Haemost 2003;90:157.
212.Pascale S, Petrucci G, Dragani A, Habib A, Zaccardi F, Pagliaccia F, et al. Aspirininsensitive thromboxane biosynthesis in essential thrombocythemia is explained by accelerated renewal of the drug target. Blood 2012;119:3595-3603.

213.Tefferi A. Overcoming «aspirin resistance» in MPN. Blood 2012;119:3377-3378.

214. Di Minno G, Silver MJ, Cerbone AM, Murphy S. Trial of repeated low-dose aspirin in diabetic angiopathy. Blood 1986;68:886-891.

215. Davis JW, Hartman CR, Lewis HD, Jr., Shelton L, Eigenberg DA, Hassanein KM, et al. Cigarette smoking--induced enhancement of platelet function: lack of prevention by aspirin in men with coronary artery disease. J Lab Clin Med 1985;105:479-483.

216. Hung J, Lam JY, Lacoste L, Letchacovski G. Cigarette smoking acutely increases platelet thrombus formation in patients with coronary artery disease taking aspirin. Circulation 1995;92:2432-2436.

217. Morrow JD, Frei B, Longmire AW, Gaziano JM, Lynch SM, Shyr Y, et al. Increase in circulating products of lipid peroxidation (F2-isoprostanes) in smokers. Smoking as a cause of oxidative damage. $\mathrm{N}$ Engl J Med 1995;332:1198-1203.

218. Reilly M, Delanty N, Lawson JA, FitzGerald GA. Modulation of oxidant stress in vivo in chronic cigarette smokers. Circulation 1996;94:19-25.

219.Weber AA, Liesener S, Schanz A, Hohlfeld T, Schror K. Habitual smoking causes an abnormality in platelet thromboxane $A_{2}$ metabolism and results in an altered susceptibility to aspirin effects. Platelets 2000;11:177-182.

220.Csiszar A, Stef G, Pacher P, Ungvari Z. Oxidative stress-induced isoprostane formation may contribute to aspirin resistance in platelets. Prostaglandins Leukot Essent Fatty Acids 2002;66:557-558.

221.Cipollone F, Ciabattoni G, Patrignani $P$, Pasquale M, Di Gregorio D, Bucciarelli T, et al. Oxidant stress and aspirin-insensitive thromboxane biosynthesis in severe unstable angina. Circulation 2000;102:1007-1013.

222.Zimmermann $N$, Kienzle $P$, Weber AA, Winter J, Gams E, Schror K, et al. Aspirin resistance after coronary artery bypass grafting. J Thorac Cardiovasc Surg 2001;121:982984.

223.Szczeklik A, Musial J, Undas A, Sanak M, Dropinski J, Tuleja E, et al. Aspirin and thrombinogenesis. Thromb Res 2003;110:345347.

224.Quick AJ. Salicylates and bleeding: the aspirin tolerance test. Am J Med Sci 1966;252:265- 
269.

225.De Gaetano G, Cerletti C. Prolongation of bleeding time by aspirin: a dual mechanism? Thromb Res 1988;50:907-912.

226. Cambria-Kiely JA, Gandhi PJ. Aspirin resistance and genetic polymorphisms. J Thromb Thrombolysis 2002;14:51-58.

227.Papafili A, Hill MR, Brull DJ, McAnulty RJ, Marshall RP, Humphries SE, et al. Common promoter variant in cyclooxygenase-2 represses gene expression: evidence of role in acute-phase inflammatory response. Arterioscler Thromb Vasc Biol 2002;22:1631-1636.

228.Halushka MK, Walker LP, Halushka PV. Genetic variation in cyclooxygenase 1: effects on response to aspirin. Clin Pharmacol Ther 2003;73:122-130.

229.Cooke GE, Bray PF, Hamlington JD, Pham DM, Goldschmidt-Clermont PJ. $\mathrm{P} 1^{\mathrm{A} 2}$ polymorphism and efficacy of aspirin. Lancet 1998;351:1253.

230.Szczeklik A, Undas A, Sanak M, Frolow M, Wegrzyn $\mathbf{W}$. Relationship between bleeding time, aspirin and the PIA1/A $A_{2}$ polymorphism of platelet glycoprotein IIIa. $\mathrm{Br}$ J Haematol 2000;110:965-967.

231. Undas A, Brummel K, Musial J, Mann KG, Szczeklik A. $\operatorname{PI}\left(A_{2}\right)$ polymorphism of beta(3) integrins is associated with enhanced thrombin generation and impaired antithrombotic action of aspirin at the site of microvascular injury. Circulation 2001;104:2666-2672.

232.Kunicki TJ. The influence of platelet collagen receptor polymorphisms in hemostasis and thrombotic disease. Arterioscler Thromb Vasc Biol 2002;22:14-20.

233. Undas A, Sydor WJ, Brummel K, Musial J, Mann KG, Szczeklik A. Aspirin alters the cardioprotective effects of the factor XIII Val34Leu polymorphism. Circulation 2003;107:17-20.

234.Gemmati D, Federici F, Campo G, Tognazzo S, Serino ML, De Mattei $M$, et al. Factor XIIIA-V34L and factor XIIIB-H95R gene variants: effects on survival in myocardial infarction patients. Mol Med 2007;13:112-120.

235. Floyd CN, Ferro A. Mechanisms of aspirin resistance. Pharmacol Ther 2014;141:69-78.

236. FitzGerald GA, Oates JA, Hawiger J, Maas RL, Roberts LJ, 2nd, Lawson JA, et al. Endogenous biosynthesis of prostacyclin and thromboxane and platelet function during chronic administration of aspirin in man. J Clin Invest $1983 ; 71: 676-688$.

237.Pulcinelli FM, Pignatelli P, Celestini A, Riondino S, Gazzaniga PP, Violi F. Inhibition of platelet aggregation by aspirin progressively decreases in long-term treated patients. J Am
Coll Cardiol 2004;43:979-984.

238.Alexander JH, Harrington RA, Tuttle RH, Berdan LG, Lincoff AM, Deckers JW, et al. Prior aspirin use predicts worse outcomes in patients with non-ST-elevation acute coronary syndromes. PURSUIT Investigators. Platelet IIb/IIIa in Unstable angina: Receptor Suppression Using Integrilin Therapy. Am J Cardiol 1999;83:1147-1151.

239.Santopinto J, Gurfinkel EP, Torres V, Mar$\cos$ E, Bozovich GE, Mautner B, et al. Prior aspirin users with acute non-ST-elevation coronary syndromes are at increased risk of cardiac events and benefit from enoxaparin. Am Heart J 2001;141:566-572.

240.Hohlfeld $T$, Weber AA, Junghans $U$, Schumacher M, Boucher M, Schror K, et al. Variable platelet response to aspirin in patients with ischemic stroke. Cerebrovasc Dis 2007;24:43-50.

241.Perneby C, Granstrom E, Beck O, Fitzgerald D, Harhen B, HjemdahI P. Optimization of an enzyme immunoassay for 11-dehydro-thromboxane $\mathrm{B}(2)$ in urine: comparison with GC-MS. Thromb Res 1999;96:427-436.

242.Bruno A, McConnell JP, Cohen SN, Tietjen GE, Wallis RA, Gorelick PB, et al. Serial urinary 11-dehydrothromboxane B2, aspirin dose, and vascular events in blacks after recent cerebral infarction. Stroke 2004;35:727730.

243. Capone ML, Tacconelli S, Sciulli MG, Grana M, Ricciotti E, Minuz $\mathbf{P}$, et al. Clinical pharmacology of platelet, monocyte, and vascular cyclooxygenase inhibition by naproxen and low-dose aspirin in healthy subjects. Circulation 2004; 109:1468-1471.

244.Eikelboom J. Aspirin resistance: does it exist and is it an important clinical problem? Clin Adv Hematol Oncol 2006;4:268-270.

245.Duke WW. The relation of blood platelets to hemorrhagic disease. Description of a method for determining the bleeding time and coagulation time and report of three cases of hemorrhagic disease relieved by transfusion. JAMA $1910 ; 55: 1185$.

246.Born GV, Cross MJ. The aggregation of blood platelets. J Physiol 1963;168:178-195.

247.Wu AH, Lewandrowski K, Gronowski AM, Grenache DG, Sokoll LJ, Magnani B. Antiquated tests within the clinical pathology laboratory. Am J Manag Care 2010;16:e220-227.

248.Peterson $P$, Hayes TE, Arkin CF, Bovill EG, Fairweather RB, Rock WA, Jr., et al. The preoperative bleeding time test lacks clinical benefit: College of American Pathologists' and American Society of Clinical Pathologists' position article. Arch Surg 1998;133:134-139. 
249.Kunicki TJ, Nugent DJ. Qualitative disorders of platelet function. In: Wintrobe's Clinical Hematology, edited by Greer JP, Arber DA, Glader $B$, List AF, Means RTJ, Paraskevas F. Philadelphia, PA: Lippincott Williams \& Wilkins, 2013, p. $1128-1142$.

250.Harrison $\mathbf{P}$, Lordkipanidze $\mathbf{M}$. Clinical test of platelet function. In: Platelets, edited by $\mathrm{Mi}-$ chelson AD. London: Academic Press, 2013, p. 519-557.

251.Kasotakis G, Pipinos, II, Lynch TG. Current evidence and clinical implications of aspirin resistance. J Vasc Surg 2009;50:1500-1510.

252. Cattaneo M. Aspirin and clopidogrel: efficacy, safety, and the issue of drug resistance. Arterioscler Thromb Vasc Biol 2004;24:1980-1987.

253.Azam SM, Jozic J. Variable platelet responsiveness to aspirin and clopidogrel: role of platelet function and genetic polymorphism testing. Transl Res 2009;154:309-313.

254.Harrison $P$, Frelinger $A L$, 3rd, Furman MI, Michelson AD. Measuring antiplatelet drug effects in the laboratory. Thromb Res 2007;120:323-336.

255.Ben-Dor I, Kleiman NS, Lev E. Assessment, mechanisms, and clinical implication of variability in platelet response to aspirin and clopidogrel therapy. Am J Cardiol 2009;104:227233.

256.Campuzano-Maya G. PFA-100: una nueva prueba de función plaquetaria sustituta del tiempo de sangría. Medicina \& Laboratorio 2013;19:411-448.

257.Guevara-Arismendy NM, Escobar-Gallo GE, Campuzano-Maya G. Utilidad clínica de la agregregometría plaquetaria. Medicina \& Laboratorio 2012;18:311-332.

258. Favaloro EJ. Clinical utility of the PFA-100. Semin Thromb Hemost 2008;34:709-733.

259. Campuzano-Maya G. Del hemograma manual al hemograma de cuarta generación. Medicina \& Laboratorio 2007;13:551-550.

260. Marques MB, Anastasi J, Ashwood E, Baron B, Fitzgerald $\mathbf{R}$, Fung $\mathbf{M}$, et al. The clinical pathologist as consultant. Am J Clin Patho 2011;135:11-12.

261.Homoncik M, Jilma B, Hergovich N, Stohlawetz P, Panzer S, Speiser W. Monitoring of aspirin (ASA) pharmacodynamics with the platelet function analyzer PFA-100. Thromb Haemost 2000;83:316-321.

262.Nimmerfall K, Mischke R. [Effect of unfractionated and low-molecular-weight heparin on platelet aggregation and in vitro bleeding time in dogs]. Dtsch Tierarztl Wochenschr 1999;106:439-444.

263.Kottke-Marchant K, Powers JB, Brooks L,
Kundu S, Christie DJ. The effect of antiplatelet drugs, heparin, and preanalytical variables on platelet function detected by the platelet function analyzer (PFA-100). Clinical and applied thrombosis/hemostasis : official journal of the International Academy of Clinical and Applied Thrombosis/Hemostasis 1999;5:122130.

264.Ortel TL, James AH, Thames EH, Moore KD, Greenberg CS. Assessment of primary hemostasis by PFA-100 analysis in a tertiary care center. Thromb Haemost 2000;84:93-97.

265.Favaloro EJ. Utility of the PFA-100 for assessing bleeding disorders and monitoring therapy: a review of analytical variables, benefits and limitations. Haemophilia 2001;7:170-179.

266. Harrison $\mathbf{P}$. Progress in the assessment of platelet function. Br J Haematol 2000;111:733744.

267. Michelson AD. Platelet function testing in cardiovascular diseases. Circulation 2004; 110:e489-493.

268.Craft RM, Chavez JJ, Bresee SJ, Wortham DC, Cohen E, Carroll RC. A novel modification of the Thrombelastograph assay, isolating platelet function, correlates with optical platelet aggregation. J Lab Clin Med 2004;143:301309.

269. Harrison P, Segal H, Blasbery $K$, Furtado C, Silver L, Rothwell PM. Screening for aspirin responsiveness after transient ischemic attack and stroke: comparison of 2 point-of-care platelet function tests with optical aggregometry. Stroke 2005;36:1001-1005.

270.Lordkipanidze $M$, Pharand $C$, Schampaert E, Turgeon J, Palisaitis DA, Diodati JG. A comparison of six major platelet function tests to determine the prevalence of aspirin resistance in patients with stable coronary artery disease. Eur Heart J 2007;28:1702-1708.

271.Cattaneo $M$, Cerletti $C$, Harrison P, Hayward CP, Kenny D, Nugent D, et al. Recommendations for the Standardization of Light Transmission Aggregometry: A Consensus of the Working Party from the Platelet Physiology Subcommittee of SSC/ISTH. J Thromb Haemost 2013.

272.Paniccia R, Priora R, Liotta AA, Abbate $R$. Platelet function tests: a comparative review. Vasc Health Risk Manag 2015;11:133-148.

273.Dawson J, Quinn T, Rafferty $M$, Higgins $\mathbf{P}$, Ray G, Lees KR, et al. Aspirin resistance and compliance with therapy. Cardiovasc Ther 2011;29:301-307.

274.Favaloro EJ, Bonar R. External quality assurance for the PFA-100(R). J Thromb Haemost 2011;9:878-880.

275.Adcock Funk DM, Lippi G, Favaloro EJ. 
Quality standards for sample processing, transportation, and storage in hemostasis testing. Semin Thromb Hemost 2012;38:576-585.

276. Laboratorio Clínico Hematológico, Manual de Procedimientos. ABC de laboratorio. Prueba de función plaquetaria por PFA-100. Medicina \& Laboratorio 2014;20:263-270.

277. Laboratorio Clínico Hematológico, Manual de Procedimientos. Agregación plaquetaria, ácido araquidónico. Medicina \& Laboratorio 2016;20:87-92.

278. Feuring $M$, Wehling $M$, Ruf $A$, Schultz A. Circadian variation of platelet function measured with the PFA-100. Platelets 2009;20:466-470.

279.Pulcinelli FM, Riondino S. More on aspirin resistance: position paper of the Working Group on Aspirin Resistance. Proposal for a Laboratory Test Guiding Algorithm. J Thromb Haemost 2006;4:485-487.

280. Hirsh J, Fuster V, Ansell J, Halperin JL, American Heart A, American College of Cardiology F. American Heart Association/ American College of Cardiology Foundation guide to warfarin therapy. Circulation 2003;107:1692-1711.

281. Baglin TP, Keeling DM, Watson HG, British Committee for Standards in $\mathbf{H}$. Guidelines on oral anticoagulation (warfarin): third edition--2005 update. $\mathrm{Br} \mathrm{J}$ Haematol 2006;132:277-285.

282.Snoep JD, Hovens MM, Eikenboom JC, van der Bom JG, Huisman MV. Association of laboratory-defined aspirin resistance with a higher risk of recurrent cardiovascular events: a systematic review and meta-analysis. Arch Intern Med 2007;167:1593-1599.

283. Krasopoulos G, Brister SJ, Beattie WS, Buchanan MR. Aspirin «resistance» and risk of cardiovascular morbidity: systematic review and meta-analysis. BMJ 2008;336:195-198.

284. Vadasz D, Sztriha LK, Sas K, Vecsei L. Aspirin and clopidogrel resistance: possible mechanisms and clinical relevance. Part II: Potential causes and laboratory tests. Ideggyogy Sz 2013;66:15-22.

285.Tarján J, Salamón A, Jager R, Poor F, Barczi V, Dinnyes J, et al. [The rate of acetylsalicylic acid non-respondents among patients hospitalized for acute coronary disease, previously undergoing secondary salicylic acid prophylaxis]. Orv Hetil 1999;140:2339-2343.

286.Schwartz KA. Aspirin resistance: a review of diagnostic methodology, mechanisms, and clinical utility. Adv Clin Chem 2006;42:81-110.

287. Cotter G, Shemesh E, Zehavi M, Dinur I, Rudnick A, Milo O, et al. Lack of aspirin ef- fect: aspirin resistance or resistance to taking aspirin? Am Heart J 2004;147:293-300.

288.Antithrombotic Trialists Collaboration. Collaborative meta-analysis of randomised trials of antiplatelet therapy for prevention of death, myocardial infarction, and stroke in high risk patients. BMJ 2002;324:71-86.

289.Tohgi H, Konno S, Tamura K, Kimura B, Kawano K. Effects of low-to-high doses of aspirin on platelet aggregability and metabolites of thromboxane $A_{2}$ and prostacyclin. Stroke 1992; 23:1400-1403.

290.Helgason $\mathrm{CM}$, Tortorice $\mathrm{KL}$, Winkler SR, Penney DW, Schuler JJ, McClelland TJ, et al. Aspirin response and failure in cerebral infarction. Stroke 1993;24:345-350.

291.Reny JL, De Moerloose $P$, Dauzat M, Fontana P. Use of the PFA-100 closure time to predict cardiovascular events in aspirin-treated cardiovascular patients: a systematic review and meta-analysis. J Thromb Haemost 2008;6:444-450.

292.Müller I, Besta F, Schulz C, Massberg S, Schonig A, Gawaz M. Prevalence of clopidogrel non-responders among patients with stable angina pectoris scheduled for elective coronary stent placement. Thromb Haemost 2003;89:783-787.

293. Matetzky S, Shenkman B, Guetta V, Shechter M, Beinart R, Goldenberg I, et al. Clopidogrel resistance is associated with increased risk of recurrent atherothrombotic events in patients with acute myocardial infarction. Circulation 2004;109:3171-3175.

294.Lev EI, Patel RT, Maresh KJ, Guthikonda S, Granada J, DeLao T, et al. Aspirin and clopidogrel drug response in patients undergoing percutaneous coronary intervention: the role of dual drug resistance. J Am Coll Cardiol 2006;47:27-33.

295.Xanthopoulou I, Stavrou EF, Kassimis G, Goudas P, Alexopoulos D. Resistance to high-maintenance dose of prasugrel treated by ticagrelor: a case report. Platelets $2013 ; 24: 239-241$.

296.Tapp L, Shantsila E, Lip GY. Role of ticagrelor in clopidogrel nonresponders: resistance is futile? Circulation 2010;121:1169-1171.

297.Samos M, Fedor M, Kovar F, Duraj L, Stanciakova L, Galajda $\mathbf{P}$, et al. Ticagrelor: a safe and effective approach for overcoming clopidogrel resistance in patients with stent thrombosis? Blood Coagul Fibrinolysis 2016;27:117120.

298.Conti CR. Is aspirin resistance a risk factor? Clin Cardiol 2005;28:163-164. 